UNIVERSIDADE DE SÃO PAULO

FACULDADE DE MEDICINA DE RIBEIRÃO PRETO

Eduardo Guidi Francisco dos Reis

\title{
PROTOCOLOS DE IMPLEMENTAÇÃO E AVALIAÇÃO DOS TRATAMENTOS DE BRAQUITERAPIA OFTÁLMICA COM RUTÊNIO-106 EM UM HOSPITAL GERAL
}


Eduardo Guidi Francisco dos Reis

\section{PROTOCOLOS DE IMPLEMENTAÇÃO E AVALIAÇÃO DOS TRATAMENTOS DE BRAQUITERAPIA OFTÁLMICA COM RUTÊNIO-106EM UM HOSPITAL GERAL}

Dissertação apresentada à Universidade de São Paulo, para a obtenção de Título de Mestre no Programa Mestrado Profissional em Ciências das Imagens e Física Médica.

Área de Física Médica, Opção: Radioterapia e Física Médica.

Orientador: Prof. Dr. Harley Francisco de Oliveira

Ribeirão Preto

Julho/ 2017 
AUTORIZO A REPRODUÇÃO E DIVULGAÇÃO TOTAL OU PARCIAL DESTE TRABALHO, POR QUALQUER MEIO CONVENCIONAL OU ELETRÔNICO, PARA FINS DE ESTUDO E PESQUISA, DESDE QUE CITADA A FONTE.

\section{FICHA CATALOGRÁFICA}

Francisco dos Reis, Eduardo Guidi

Protocolos de implementação e avaliação dos tratamentos de braquiterapia oftálmica com Rutênio-106 em um hospital geral / Francisco dos Reis, Eduardo Guidi; Orientador,Harley Francisco de Oliveira. -2017.

72 f. :16 il.

Dissertação (Mestrado) - Faculdade de Medicina de Ribeirão Preto da Universidade de São Paulo. Departamento de Clínica Médica. Área de Concentração: Investigação Biomédica (Programa Mestrado Profissional em Ciências das Imagens e Física Médica Área de Física Médica, Opção: Radioterapia e Física Médica).

Versão original.

1) Braquiterapia Oftálmica; 2) Melanoma Uveal; 3) Rutênio-106;

4) Radioterapia. 


\section{FOLHA DE APROVAÇÃO}

Francisco dos Reis, Eduardo Guidi

PROTOCOLOS DE IMPLEMENTAÇÃO E AVALIAÇÃO DOS TRATAMENTOS DE BRAQUITERAPIA OFTÁLMICA COM RUTÊNIO-106 EM UM HOSPITAL GERAL.

Dissertação apresentada à Universidade de São Paulo, para a obtenção de Título de Mestre no Programa Mestrado Profissional em Ciências das Imagens e Física Médica - Área de Física Médica, Opção: Radioterapia e Física Médica.

Aprovado em:

Banca examinadora:

Prof. Dr.

Instituição: Assinatura:

Prof. Dr.

Instituição: Assinatura:

Prof. Dr. Instituição: Assinatura: 


\section{AGRADECIMENTOS}

Primeiramente agradeço aos meus pais e minha família por terem me dado o meu maior bem, meu diploma e caráter, sempre me incentivando e não poupando esforços para minha educação e bem-estar.

Agradeço a Deus por ter saúde e motivação para realizar meu trabalho da melhor forma possível dia após dia.

Agradeço a minha esposa Vanessa, por estar sempre ao meu lado, usando o seu tempo para me ajudar e incentivar, me deixando mais tranquilo para dedicar ao serviço.

Agradeço imensamente a toda estrutura e profissionais envolvidos na Santa Casa de Misericórdia de Passos - MG, pois sem eles esse trabalho não seria possível.

Agradeço imensamente a equipe de Radioterapia, em especial ao Dr. Rodrigo, Dra. Joana, Lívia, pelas grandes discussões e conhecimentos trocados na elaboração e implementação do serviço de Braquiterapia Oftálmica.

Agradeço a equipe da Oftalmologia, aos médicos Wesley, Fábio, Patrick e Thales, que foram os precursores da criação desse serviço, além de serem excelentes profissionais para se trabalharem.

Agradeço ao meu orientador e amigo Dr. Harley, que sempre esteve ao meu lado ajudando e motivando desde minha residência até hoje.

"A mente que se abre a uma nova ideia jamais voltará ao seu tamanho original" Albert Einstein

"Vê mais longe a gaivota que voa mais alto"

Richard Bach 


\section{RESUMO}

Título: PROTOCOLOS DE IMPLEMENTAÇÃO E AVALIAÇÃO DOS TRATAMENTOS DE BRAQUITERAPIA OFTÁLMICA COM RUTÊNIO-106 EM UM HOSPITAL GERAL. $72 f$.

A Braquiterapia oftálmica utiliza radionuclídeos, como o Rutênio-106 no tratamento de melanomas uveais e outras neoplasias oculares. Para realização desse procedimento é necessária uma interação da equipe multidisciplinar principalmente entre a Oftalmologia, Oncologia, Radioterapia, Física Médica e Enfermagem, envolvendo estrutura física e profissionais qualificados para garantir os processos e resultados do procedimento. Este estudo tem o objetivo de avaliar os primeiros tratamentos de braquiterapia oftálmica com Rutênio-106 e também estabelecer protocolos e processos para implementação da técnica em um Hospital Geral. Os resultados obtidos para os primeiros 11 casos tratados entre 2015 e 2017, sendo 10 melanomas e 1 hemangioma, evidenciaram baixa toxicidade aguda. Foram analisados 5 pacientes com seguimento de 5 a 13 meses. Houve regressão da lesão em todos os pacientes, com média de $28 \%$ no ápice e $12 \%$ na base no período de até 12 meses, sendo observado uma regressão progressiva durante o período de avaliação. Os protocolos foram utilizados e validados durante todas as etapas do tratamento. O uso do Ru-106 mostra-se alternativa viável no tratamento de lesões oculares, sendo primordial a capacitação e integração da equipe e seguimento de protocolos para o êxito do tratamento.

Palavras Chaves: Braquiterapia Oftálmica; Melanoma Uveal; Rutênio-106; Radioterapia. 


\section{ABSTRACT}

Title: IMPLEMENTATION PROTOCOLS AND TREATMENTS EVALUATION OF 106-RUTENIUM OPHTHALMIC BRACHYTHERAPY IN A GENERAL HOSPITAL.

Ophthalmic Brachytherapy uses radionuclides, such as Ruthenium-106 in the treatment of uveal melanomas and other ocular tumors. For this procedure is necessary a multidisciplinary interaction between Ophthalmology, Oncology, Radiotherapy, Medical Physics and Nursing, involving physical structure and qualified professionals to guarantee the processes and results of the procedure. This study aims to evaluate the first ophthalmic brachytherapy treatments with ruthenium106 and also to establish protocols and processes for the implementation of this service in a General Hospital. The results obtained for the first 11 cases treated between 2015 and 2017, being 10 melanomas and 1 hemangioma, showed low acute toxicity. Five patients were followed up for 5 to 13 months. There was regression of the lesion in all of these patients, with a mean of $28 \%$ at the apex and $12 \%$ at the base in the period close to 1 year, with a progressive regression during the evaluation period. The protocols were used and validated during all stages of treatment. The use of $106-\mathrm{Ru}$ is a viable alternative in the treatment of ocular tumors, being the team qualification and the correct follow-up of the protocols crucial for the treatment success.

Keywords: Ophtalmic Brachytherapy, Uveal Melanoma, 106-Ru; Radiotherapy. 


\section{LISTA DE FIGURAS:}

Figura 1: llustração mostrando partes do olho, incluindo a conjuntiva, da câmara anterior, córnea, lente, íris, corpo ciliar, órbita, nervo óptico, coroide, retina e esclera.

Figura 2: Ilustração mostrando a distribuição de dose do I-125 à esquerda e Ru-106

Figura 3: Ultrassom com as medidas do tumor do paciente 2 antes da Braquiterapia com Ru-106. 34

Figura 4: Ultrassom com as medidas do tumor do paciente 213 meses após da Braquiterapia com Ru-106.

Figura 5: Ultrassom com as medidas do tumor do paciente 1 antes da Braquiterapia com Ru-106.

Figura 6: Ultrassom com as medidas do tumor do paciente 112 meses após da Braquiterapia com Ru-106.

Figura 7: Á esquerda retinografia do paciente 2 antes da Braquiterapia, e à direita 11 meses de seguimento. 36

Figura 8: Retinografia do Paciente 1 antes da Braquiterapia com Ru-106. 36

Figura 9: Retinografia do Paciente ,1 10 meses após a Braquiterapia com Ru-106.37

Figura 10: Placa de Rutênio-106 do tipo CCB. 49

Figura 11: Design da Placa de Rutênio 106, com a composição otimizada para uma melhor distribuição de dose e blindagem. 49

Figura 12: Tabela da variação da taxa de dose da placa de Rutênio -106 com a profundidade. 50

Figura 13: 16 diferentes tipos de placas de Rutênio -106. 51

Figura 14: Esquema dos decaimentos radioativos do $\mathrm{Ru}-106$ até $\mathrm{Pd}-106$. 52

Figura 15: Etapas do procedimento cirúrgico, fotos do arquivo pessoal. 61

Figura 16: Distribuição de dose da placa de Ru-106. 65 


\section{LISTA DE ABREVIAÇÕES}

TTT - Termoterapia Transpupilar a Laser

VEGF - Fator de crescimento endotelial-vascular

COMS - Estudo de Melanoma Maligno Cooperativo na América do Norte

ROS - Espécies oxigênio reativas

Gy - Gray

LDR - Braquiterapia de baixa taxa de dose

CT - Tomografia Computadorizada

RNM - Ressonância Magnética

CTV - Volume tumoral clínico

PTV - Volume Tumoral Planejado

CNEN - Comissão Nacional de Energia Nuclear

Bq- Becquerel

$\mathrm{Ci}-$ Curie

IOE(s) - Indivíduo(s) Ocupacionamente Exposto (s)

Sv - Sievert

ANS - Agência Nacional de Saúde

SUS - Sistema Único de Saúde 


\section{SUMÁRIO}

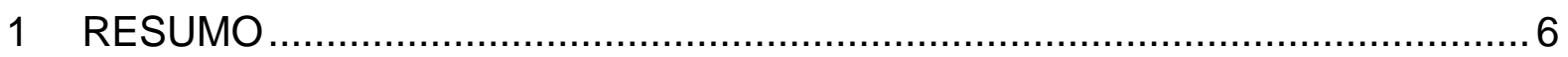

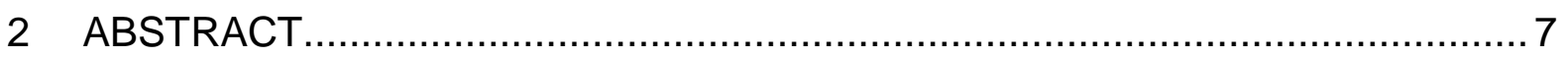

3 LISTA DE FIGURAS:

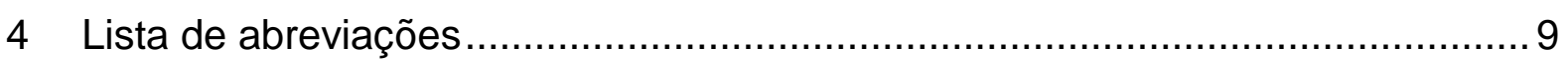

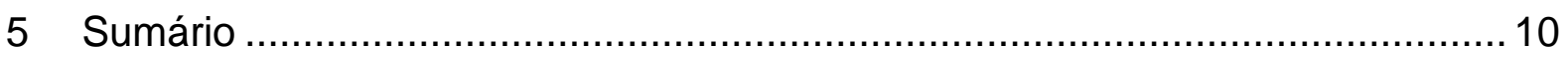

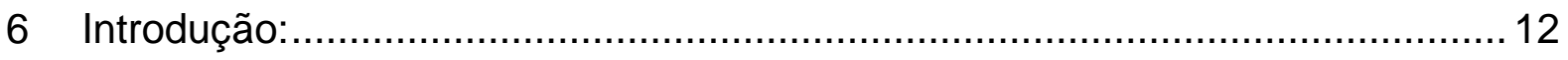

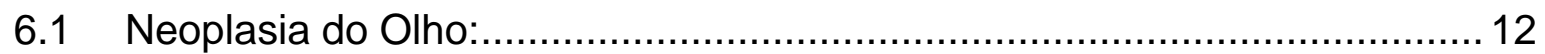

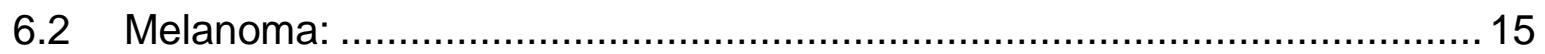

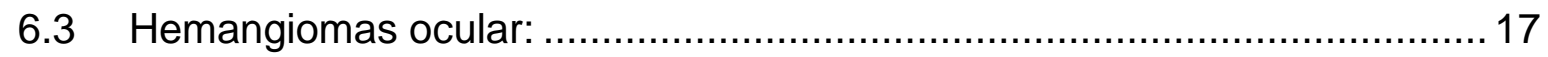

6.4 Tratamento dos tumores oculares:..................................................... 17

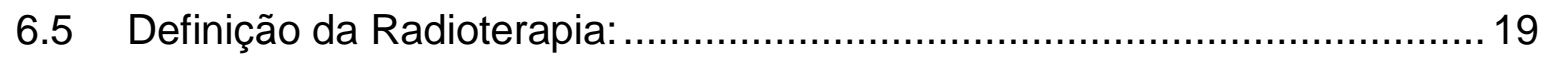

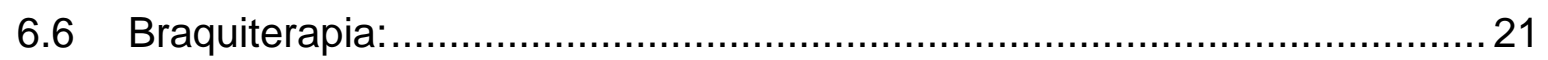

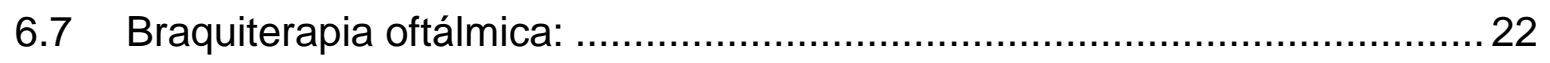

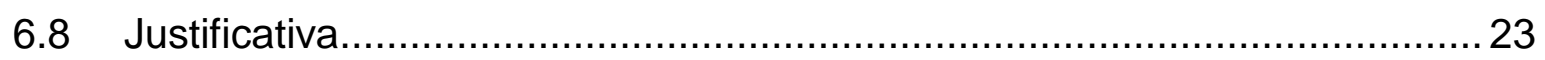

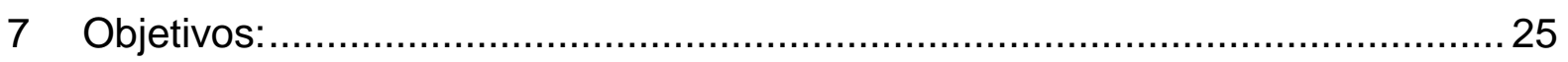

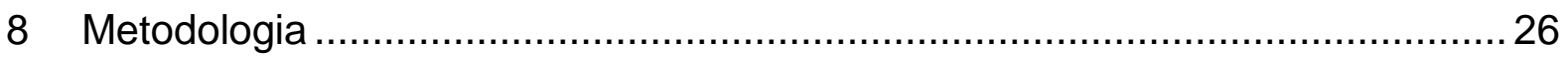

8.1 Procedimento de braquiterapia oftálmica com Ru-106 ............................ 28

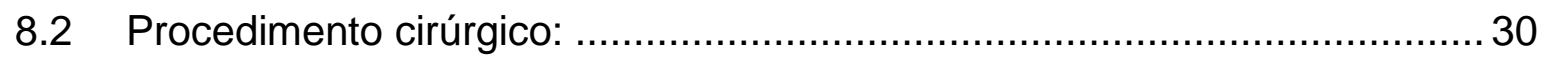

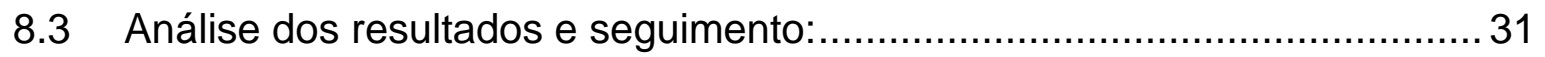

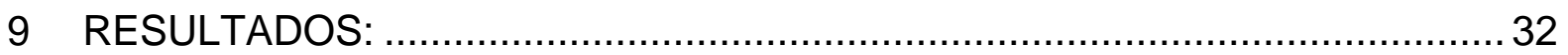

10 DISCUSSÃO:

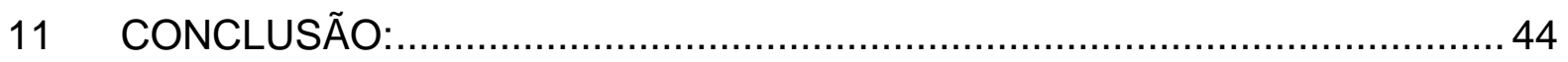

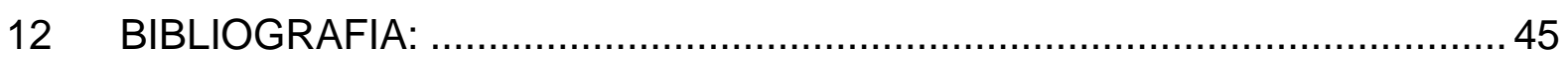

13 ANEXO 1: PROTOCOLO DE BRAQUITERAPIA OFTALMICA COM Ru-106: 
13.1 Característica e Descrição técnica:.................................................... 48

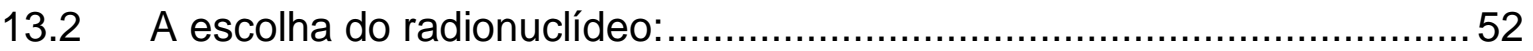

14 Protocolos de implementação: ................................................................ 53

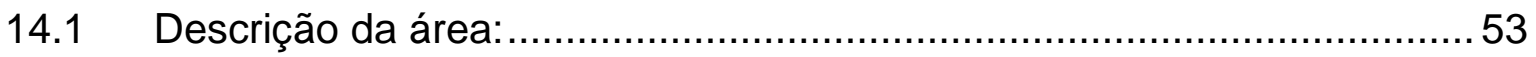

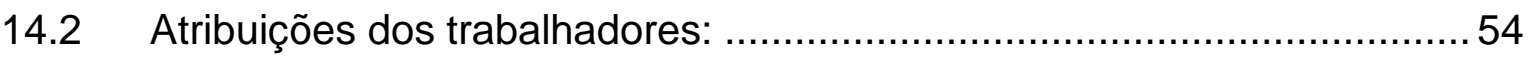

14.3 Instruções para o procedimento de Braquiterapia Oftálmica de baixa taxa

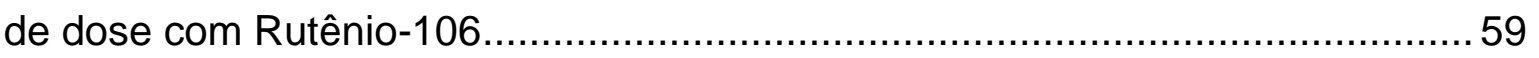

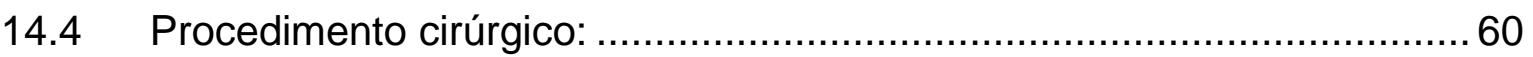

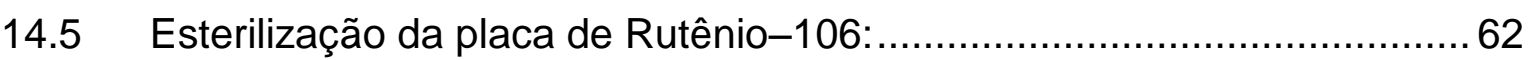

14.6 Procedimentos de Controle de Qualidade .............................................63

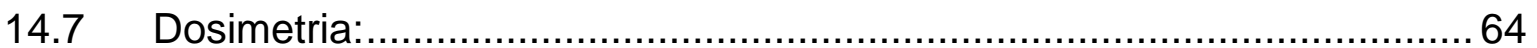

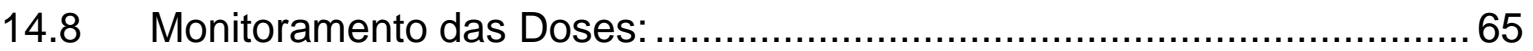

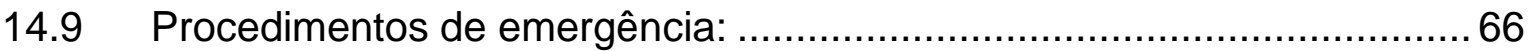

14.10 PROCEDIMENTOS DA ENFERMAGEM PARA PACIENTES COM FONTES DE RUTÊNIO-106 PLACAS OFTÁLMICAS ………………............... 67

15 ANEXO 2 - FICHA DE ENCAMINHAMENTO DA OFTALMOLOGIA..............71

16 ANEXO 3: FICHA DE TRATAMENTO DESENVOLVIDA DO HOSPITAL REGIONAL DO CÂNCER DE PASSOS - MG........................................................ 72 


\section{INTRODUÇÃO:}

\subsection{Neoplasia do Olho:}

As neoplasias do bulbo ocular e anexos, integram os tumores que possuem origem primária nestas estruturas ou provenientes de metástases. São tumores raros que podem acometer qualquer estrutura do olho ou anexos, como conjuntiva, retina, nervo óptico ou córnea ${ }^{1}$.

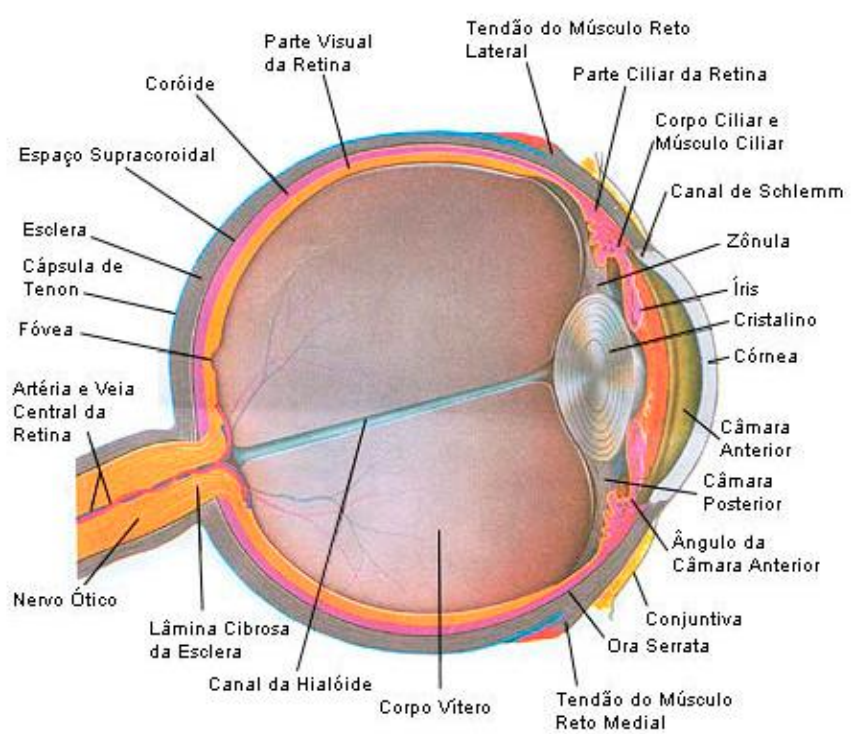

Figura 1: Ilustração mostrando partes do olho, incluindo a conjuntiva, da câmara anterior, córnea, lente, íris, corpo ciliar, órbita, nervo óptico, coroide, retina e esclera.(disponível em: http://www.angelicavilela.com.br/wpcontent/uploads/2015/08/olho1.jpg)

O bulbo ocular é a estrutura principal do olho preenchida por um material gelatinoso denominado humor vítreo. O bulbo ocular é subdividido em três camadas. A primeira camada é chamada de camada fibrosa e é constituída pela córnea e pela esclera, que reveste externamente o bulbo ocular. A córnea é a camada mais anterior, transparente, avascular, com função refrativa para permitir a passagem da luz para a atingir a retina afim de formar a imagem. A esclera é a 
camada mais posterior, contínua com a córnea, opaca, mais vascularizada, a qual impede a passagem de luz por ela, permitindo que o interior do bulbo ocular fique em total escuridão, facilitando a formação da imagem. A úvea é a camada intermediária, vascularizada, cuja função é principalmente de nutrição das estruturas mais internas do bulbo ocular, ela se divide em íris, corpo ciliar e coroide, onde se desenvolvem a maioria dos melanomas do olho. A parte mais anterior da úvea, a íris é a região onde se dá a cor dos olhos (azul, verde, castanho claro, escuro) e tem a função de limitar a entrada de luz no interior do bulbo ocular por um diafragma extremamente móvel que é a pupila, um orifício cujo diâmetro é regulado pelo sistema nervoso autônomo, o parassimpático que inerva o músculo esfíncter da pupila que causa o seu fechamento (miose) e o simpático que inerva o músculo dilatador da pupila que causa a sua abertura (midríase). O corpo ciliar é dividido em pars plicata (mais anterior) e pars plana (mais posterior). A pars plicata é constituída pelo músculo ciliar responsável pela acomodação e pelo epitélio pigmentário secretor, responsável pela produção do humor aquoso que vai preencher a câmara anterior (espaço entre a córnea, íris e cristalino), que vai ser responsável por manter a pressão intra-ocular. A coroide é um tecido vascularizado com a finalidade de nutrir a parte mais externa da retina, por difusão. Ela é a região do corpo que mais sangue tem por milímetro cúbico, mostrando a extrema necessidade de nutrição demandada pela retina ${ }^{1}$.

A retina é a camada mais interna localizada no segmento posterior do bulbo ocular e é constituída por dez camadas com a finalidade de processar a imagem recebida do mundo exterior. Esta estrutura transmite informação que vai ser enviada através das vias ópticas até o córtex calcarino onde a imagem vai ser processada e tornada em visão. ${ }^{1}$. 
Existem três câmaras no interior do bulbo ocular, a câmara anterior, posterior preenchidas pelo humor aquoso e a câmara vítrea preenchida pelo corpo vítreo, estrutura essa que é formada no período fetal e preenche dois terços do volume intraocular e é aderida à retina, vasos, disco óptico e estruturas anteriores como cristalino e o corpo ciliar.

O cristalino é uma lente biconvexa, move, fixada em 360 graus ao corpo ciliar através de pequenas cordas elásticas chamadas zonulas que permitem a modificação da espessura no processo da acomodação visual, que possibilita a focalização dos objetos tanto para longe e para perto.

A órbita é uma estrutura de forma cônica com abertura maior anterior e é constituída de um arcabouço ósseo e de tecidos que envolvem o bulbo ocular, incluindo músculos, nervos, vasos, tecido conjuntivo, glândula lacrimal principal, gordura, que permitem o funcionamento e movimentação do bulbo ocular como uma câmera para captar imagem em todas as direções sem limitações.

Os anexos são constituídos pelo supercílio, pálpebras inferior e superior, cílios, conjuntiva e sistema lacrimal (glândula lacrimal e vias de drenagem da lágrima).

Existem diferentes tipos de neoplasia do olho. As neoplasias que acometem o bulbo ocular são chamadas intraoculares, sendo estes tumores possíveis de serem tratados por várias técnicas, entre elas a braquiterapia oftálmica. Das neoplasias intraoculares primárias nos adultos, o melanoma primário do olho é o mais prevalente, seguido pelo linfoma intraocular primário da retina e sistema nervoso central. Em crianças, o retinoblastoma é a neoplasia intraocular primária mais comum ${ }^{2}$.

Neoplasias intraoculares secundárias metastáticas tem origem primária principalmente em mama e pulmão². 


\subsection{Melanoma:}

O melanoma ocular e o retinoblastoma são os tumores oculares mais comumente encontrados em pacientes adultos e pediátricos, respectivamente.

Melanoma do olho tem incidência de aproximadamente 2 a 8 casos por milhão de habitantes por ano em caucasianos. A incidência está relacionada a cor do olho, sendo menor em olhos castanhos. Mais de $90 \%$ envolve a coroide, o restante está confinado entre irís e corpo ciliar. Ambos os sexos são afetados em iguais números. O pico de incidência está em torno de 60 anos. A sobrevida é alta para os tumores iniciais $^{2,3}$.

Os melanomas uveais são tumores solitários que surgem em um olho, tomando sua origem da parede vascular do olho. Como os vasos retinianos sobrejacentes raramente alimentam o tumor, os melanomas oculares são primariamente dependentes dos vasos uveais basais.

O melanoma coroidal geralmente apresenta-se nodular e pigmentado, bem definido, com uma base arredondada ou elíptica. O principal padrão de crescimento (75\%) é para a parte interna do globo, se espalhando ao longo da coróide ou ao longo da parte interna da esclera (até 50\%). A retina sobrejacente é mais frequentemente danificada por várias razões (alterações vasculares). Quase todos os melanomas coróides levam a um desprendimento seroso da retina. O nervo óptico quase nunca é infiltrado, nem mesmo em tumores justapapilares ${ }^{4}$.

Raramente, a extensão extraescleral é observada. Os tumores coroidais infiltrativos planos e difusos são raros. A quantidade de pigmentação no melanoma coróide varia significativamente. Além de seu crescimento nodular, o melanoma do corpo ciliar também pode se estender para a parte posterior do globo ao longo da úvea e / ou da esclera e na parte anterior para a íris. O ângulo iridocorneal pode ser 
infiltrado precocemente, o que pode levar a um glaucoma secundário. A lente também pode ser deslocada devido ao crescimento do tumor.

O melanoma da íris é geralmente apresentado como lesão plana pigmentada e devido ao seu aspecto clínico é detectado numa fase precoce.

A maioria dos melanomas uveais está localizada na coróide $(70 \%)$, o resto no corpo ciliar (25\%) e na íris $(5 \%)^{2}$.

A histopatologia revela diferentes tipos de melanoma uveal com prognóstico diferente: melanoma de células fusiformes (melhor prognóstico), melanoma com uma quantidade significativa de células epitelióides (prognóstico intermediário), melanoma de células epitelióides (mau prognóstico). O diagnóstico clínico do melanoma uveal é adequado para o tratamento, a verificação histopatológica não é necessária.

Com um bom controle local, o prognóstico é correlacionado com metástases à distância, que são mais observadas no fígado (90\%), e podem ocorrer após um longo período após o sucesso do tratamento local (até mais de 20 anos). 0 recrescimento tumoral é um fator de risco significativo para a doença metastática. As metástases ao diagnóstico são incomuns ${ }^{5}$.

Em um estudo com 8033 pacientes, a taxa de metástase em 10 anos para melanomas com espessura de 0 a $3 \mathrm{~mm}$ foi de $11.5 \%$, para 3.1 a $8 \mathrm{~mm}$ foi $25.5 \%$ e para lesões maiores de $8 \mathrm{~mm}$ foi de $49.2 \%{ }^{6}$.

A citogenética e genética molecular tem grande influência no prognóstico do melanoma uveal. Perda completa ou parcial do cromossomo 3, ou anormalidades no cromossomo 1 são clinicamente relevantes devido a sua correlação com o risco de morte por metástases. A perda do cromossomo 3 é associada a uma redução na probabilidade de sobrevida em 5 anos de $100 \%$ a $50 \%{ }^{7}$. 


\subsection{Hemangiomas ocular:}

O hemangioma ocular é um tumor benigno decorrente do crescimento anormal de vasos sanguíneos do olho ou órbita. O subtipo capilar pode acometer pálpebras, superfície ou anexos do olho. Quando isso acontece, o hemangioma pode interferir com o desenvolvimento normal, principalmente em crianças, levando a ambliopia e glaucoma. Os hemangiomas desaparecem gradualmente ao longo do tempo, sendo que $90 \%$ desapareceram até a idade de nove anos. A persistência do hemangioma em adultos geralmente é assintomática, porém nos pacientes com alterações funcionais a RT é uma das alternativas de tratamento utilizando baixas doses, em torno de 20 Gy no ápice, com regressão tumoral e redução do fluido sub-retiniano em todos os pacientes e melhora da acuidade visual em $53 \%{ }^{8}$.

\subsection{Tratamento dos tumores oculares:}

A enucleação é um tratamento tradicional que consiste na remoção total do bulbo ocular, já a Radioterapia oftálmica é um método alternativo que possibilita a preservação do olho. A teleterapia utiliza radiação de fótons e de prótons ao passo que braquiterapia utiliza placas com diferentes tipos de radioisótopos encapsulados e apresenta menores efeitos colaterais que aqueles apresentados pela teleterapia.

A braquiterapia com a utilização de placas oftalmológicas é uma boa alternativa para o controle e tratamento de tumores da região da úvea e retina, pois permite o posicionamento do material radioativo na superfície da esclera e administração de dose em volume alvo. Comparado à teleterapia, a braquiterapia permite liberar altas doses de radiação diretamente sobre o tumor, minimizando os efeitos nos tecidos adjacentes. Sua indicação depende de vários fatores, tais como a espessura, diâmetro e localização do tumor, bem como disponibilidade de diferentes tipos de técnicas de radioterapia. Muitas vezes, a braquiterapia é 
combinada com outrasformas de tratamento oftalmológico local, principalmente a Termoterapia Transpupilar a Laser (TTT) e uso de quimioterápicos, principalmente o Bevacizumab, um anticorpo monoclonal que bloqueia a ação do fator de crescimento endotelial-vascular (VEGF; do inglês: Vascular Endothelial Growth Factor).

Ensaio randomizado realizado pelo grupo de Estudo de Melanoma Maligno Cooperativo na América do Norte (COMS) comparando enucleação e radioterapia com placa de iodo-125, com 660 pacientes evidenciaram que as taxas de eram semelhantes, com cerca de $81 \%$ SG em 5 anos e $65 \%$ em 10 anos $^{3}$.

Em grandes tumores (> $10 \mathrm{~mm}$ em ápice) a enucleação apresenta melhor controle local e menor morbidade ocular. Nestes casos, a enucleação representa um procedimento simples sem morbidade como observados após a RT, que por sua vez possui altas taxas de falha local e morbidade (por exemplo, desprendimento de retina, glaucoma neovascular), e, inclusive sendo necessária a enucleação em casos de recidiva ou persistência da doença. Outras modalidades que podem ser utilizadas são a teleterapia com prótons ou íons pesados, ainda não existentes no Brasil, e a Radioterapia Estereotáxica, que ainda apresentam altas taxas de morbidade ${ }^{9}$.

Diversas modalidades terapêuticas para o manejo do melanoma uveal tem evoluído nas últimas décadas. O consenso atual é o tratamento multimodal, combinado para atingirem altas taxas de controle local e minimizar as complicações. Estas combinações são dependentes das diferentes técnicas disponíveis no serviço, das dimensões, dos formatos e localização do tumor, considerando-se também as prioridades individuais (visão $x$ controle tumoral) ${ }^{9}$. 


\subsection{Definição da Radioterapia:}

A radioterapia promove o tratamento de doenças, principalmente neoplasias, através da radiação ionizante. Na célula irradiada há produção de danos letais que levam à morte celular, e danos sub-letais e potencialmente letais que provocam alterações nos mecanismos celulares de replicação e podem ser reparados. O objetivo da radioterapia é a deposição de dose definida de radiação a um volume específico de tecido ("volume alvo"), compreendendo o leito tumoral e, quando indicado, os tecidos adjacentes, principalmente linfonodos regionais, onde células tumorais podem ser encontradas. Tem a intenção de promover dano letal ás células tumorais poupando tecidos normais circunvizinhos. A deposição de dose homogênea é um processo complexo que, para cada paciente individual, envolve realização de exames para melhor definição do volume alvo, de decisões na programação da dose total, do fracionamento e da escolha do tipo de radiação, energia utilizada e do método de tratamento apropriado. A decisão terapêutica no tratamento radioterápico dependendo da extensão da doença, da condição geral do paciente, do objetivo do tratamento, radical ou paliativo, ponderando os riscos e benefícios deste tratamento para cada paciente.

Radioterapia externa é a modalidade mais comum de radioterapia, sendo mais amplamente utilizado. Implica o uso da radiação de uma fonte situada a uma distância definida do volume alvo, sem contato direto. Vários tipos de radiação estão disponíveis, e as técnicas diferentes são empregadas para conseguir o efeito desejado. A braquiterapia será apresentada adiante.

Os efeitos biológicos da radiação ionizante nos tecidos ocorrem por deposição de energia. Inicialmente há interação do estímulo físico com as moléculas de água, formando íons pelo processo de hidrólise da água. Devido à sua alta taxa de 
crescimento as neoplasias malignas tendem a ter maior sensibilidade à radiação quando comparada aos tecidos normais que circundam o tumor, o mesmo ocorre entres as linhagens tumorais conforme seu estágio proliferativo. A mitose e a fase final da G2 são as fases mais radiossensíveis do ciclo celular.

As espécies oxigênio reativas (ROS) reagem com as moléculas de RNA e DNA, gerando alterações letais ou sub-letais, inibindo a proliferação celular. O principal efeito celular das radiações ionizantes consiste em danos à molécula de DNA, provocados por elétrons livres e ROS; sendo estes últimos, os mais importantes no caso das radiações comumente utilizadas na prática radioterápica. ROS são altamente reativos, com vida curta, sendo caracterizados pela presença de elétrons não-pareados e reativos. Radicais do solvente (água) podem participar de algumas reações, particularmente na subtração do hidrogênio e na adição de ligações de carbono-carbono insaturados e transformação de moléculas-alvo em ROS intermediários de vida curta, que subsequentemente revertem-se para produtos estáveis, porém danificados. Para a radiação eletromagnética ionizante esparsa, dois terços do dano são atribuídos à ação indireta, sendo o radical $\mathrm{OH}^{-} \mathrm{o}$ de maior poder danificador. Danos pela ação indireta podem ser modificados por agentes químicos, como o oxigênio, que fixa os danos produzidos pelos radicais $\operatorname{livres}^{10}$.

Imediatamente após a exposição à radiação, o DNA intracelular apresenta danos extensos, sendo estimado que, para cada célula morta por radiação eletromagnética ionizante esparsa, há aproximadamente 1000 danos produzidos em bases, 1000 quebras em 1 dos filamentos da dupla-hélice e 40 quebras em ambos os filamentos da dupla-hélice. Entretanto, as células têm mecanismos enzimáticos, os quais agem para manter a integridade do seu material genético em face aos 
agentes que possam alterar a sequência de bases do DNA ou sua estrutura. Nas células normais, muitos danos induzidos por radiação são reparados. A eficiência com que os mesmos são reparados é um fator importante para a determinação de sua radiossensibilidade. Quando se avalia a resposta clínica aos efeitos radiobiológicos, o emprego de altas doses de radiação por fração permite melhores resultados terapêutico ${ }^{10}$.

\subsection{Braquiterapia:}

A braquiterapia é o uso da radiação ionizante muito próxima ou em contato com a região a ser tratada. Braquiterapia é um protocolo de escalonamento conformacional de dose que reduz o risco de câncer residual e de recidiva tumoral. Esta modalidade terapêutica de radiação permite que radioisótopos sejam implantados em região próxima do tumor, limitando a dose nos tecidos normais adjacentes.

A braquiterapia de baixa taxa de dose (LDR; do inglês low dose rate) vem sendo utilizada por quase um século no tratamento de diferentes tipos de câncer. LDR é definida como uma dose de radiação de 0,4 - 2 Gy/h, enquanto braquiterapia de alta taxa de dose (HDR) possui uma dose acima de 12 Gy/h. LDR utiliza posições fixas do radioisótopo no cálculo da dose no ponto de prescrição. As doses podem ser modificadas com a utilização de fontes de atividades diferentes. Tem a vantagem dos parâmetros do tratamento padrão estar bem definidos na literatura, como as doses, o planejamento, o tempo de tratamento e o número baixo de inserções. Porém a exposição da equipe médica à radiação, a necessidade de aparato cirúrgico com anestesia, a internação por longo período e a limitada possibilidade de otimização da dose de prescrição são alguns fatores restritivos ao uso da $\operatorname{LDR}^{11}$. 


\subsection{Braquiterapia oftálmica:}

$\mathrm{Na}$ maioria dos centros, a primeira opção de tratamento das neoplasias intraoculares é a braquiterapia, utilizando placas de Ru-106ou I-125. Alguns centros podem usar combinação de radioisótopos, incluindo Sr-90 e Pd-106 ${ }^{12}$.

Placas de l-125 emitem radiação gama e podem tratar com sucesso lesões com até $10 \mathrm{~mm}$ de espessura, no entanto, deposita doses elevadas em outras estruturas oculares saudáveis. Existem modelos de placas que reduzem o espalhamento lateral da radiação, colimando a dose em tecidos normais.

Placas de Rutênio-106 são geralmente indicadas para lesões de até $6 \mathrm{~mm}$ de espessura, devido ao limitado alcance das partículas beta e alta dose na esclera, embora alguns estudos tenham avaliado sua utilização em lesões maiores com resultados satisfatórios quanto ao controle tumoral e efeitos colaterais aceitáveis. Dependendo da localização da lesão, não é possível colimar a radiação para reduzir os efeitos colaterais no disco óptico e na fóvea 4 .

A distribuição de dose em 2D, observada na figura 2, para um cálculo de dose de 85 Gy no ápice com I-125 à esquerda e Ru-106 à direita. Pela figura nota-se que para lesões superficiais, o Ru-106 deposita menor dose em áreas de tecido normal. 


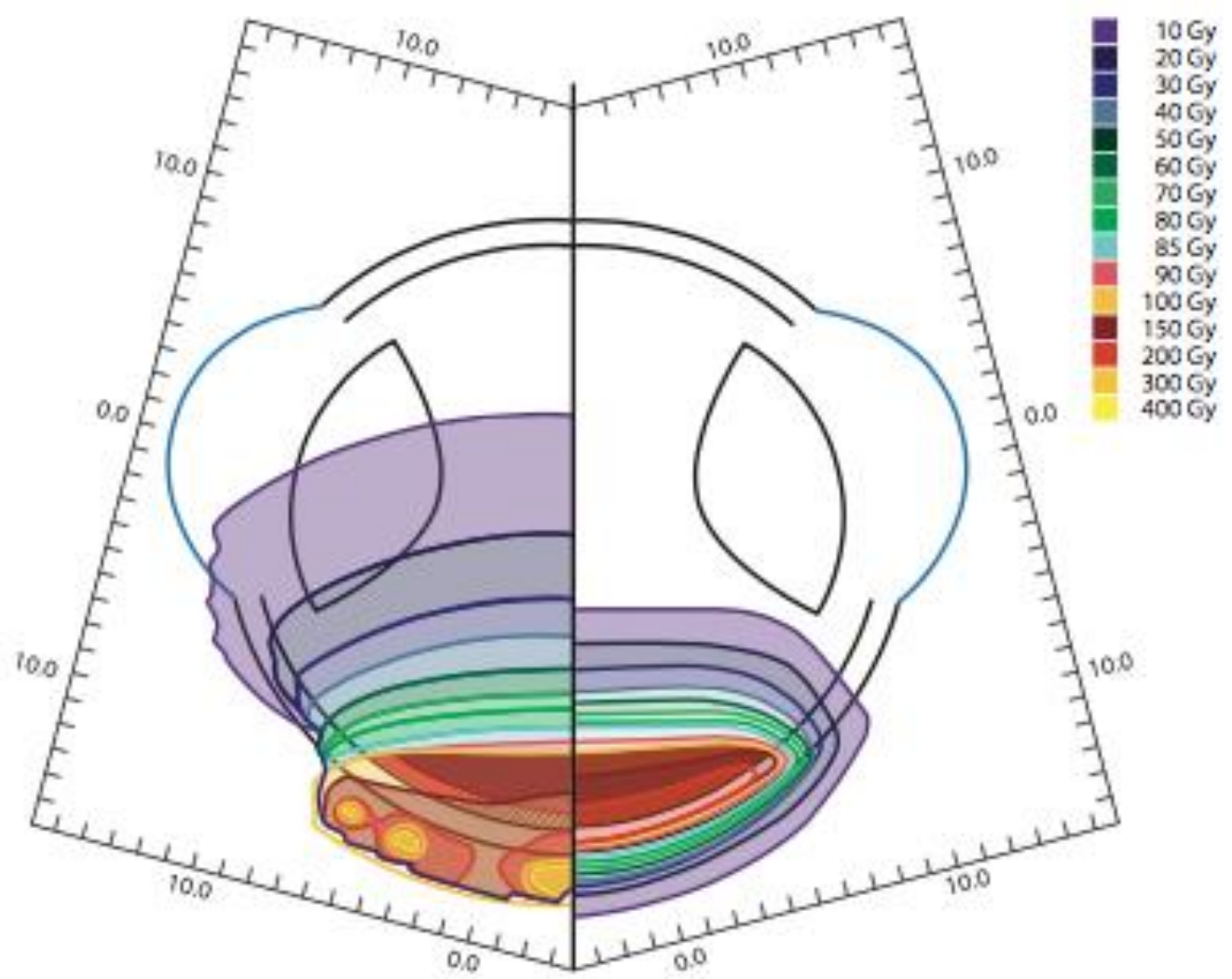

Figura 2: Ilustração mostrando a distribuição de dose do l-125 à esquerda e Ru-106.(disponível em http://www.bebig.com/index.php?id=562)

A descrição sobre a fonte de Rutênio de 106, com suas características físicas, descrição da técnica, o porquê da aquisição desse isótopo radioativo ao invés do lodo - 125, e outros procedimentos relacionados à técnica, estão detalhados no item 13.

\subsection{Justificativa}

Foram pelo menos oito anos intensa programação e estudos entre os membros envolvidos e a direção do Hospital para a implementação da Braquiterapia Oftálmica. Como mencionado nesse trabalho, é necessária uma equipe 
multidisciplinar qualificada e uma adequada estrutura física para realização deste procedimento.

Quando a Instituição se sentiu preparada para aquisição das primeiras placas de Rutênio-106, foi necessário a elaboração de um plano de radioproteção a ser submetido a Comissão Nacional de Energia Nuclear (CNEN), contendo todas as informações necessárias para obter essa licença de importação descritas adiante.

Foi necessária também ampla revisão da literatura para embasar a criação dos protocolos clínicos do serviço, levando em consideração as doses nos volumes alvos e órgãos de riscos, critérios de inclusão e exclusão, e sobre o seguimento desses pacientes que pretendemos apresentar nesta dissertação. 


\section{OBJETIVOS:}

Avaliar os primeiros tratamentos de braquiterapia oftálmica com Rutênio-106.

Propor protocolos de implementação de braquiterapia oftálmica com Rutênio106 em um Hospital Geral. 


\section{METODOLOGIA}

Estudo descritivo prospectivo avaliando 11 pacientes com diagnóstico de tumores intra-oculares, sendo 10 pacientes com melanoma uveal unilateral e 1 paciente com hemangioma de coroide, submetidos à Braquiterapia oftálmica utilizando placa de Ru-106, tratados no Hospital do Câncer de Passos, entre 2015 a 2017.

Os critérios de inclusão foram:

1. Estadiamento T1 a T3, com tumores de $2-7 \mathrm{~mm}$ de espessura, combinada ou não a TTT ou quimioterapia;

2. Sem contra-indicações cirúrgicas;

3. Sem evidencia de metástase à distância.

Os critérios de exclusão foram:

1. Tumores com extensão T4 extraocular;

2. Diâmetros basais que excedem $8 \mathrm{~mm}$ de espessura;

3. Tumores próximos do disco óptico e da mácula;

4. Olhos cegos e dolorosos;

5. Sem visão de percepção de luz.

A avaliação inicial é realizada por oftalmologista do serviço com experiência no diagnóstico e manejo do melanoma uveal.

Os seguintes exames diagnósticos devem ser realizados:

Exames clínicos: história clínica, oftalmoscopia binocular indireta com fotodocumentação (morfologia, topografia, tamanho do tumor) e desenho esquemático; exame de lâmpada de fenda e transiluminação. Poderão ser solicitados angiografia por fluorescência; ultrassonografia (padronizada A e B): dimensões tumorais (espessura, diâmetro) e topografia. 
As informações obtidas serão relatadas em prontuário próprio e encaminhadas ao rádio-oncologista. Após a avaliação dos exames realizados pelo oftalmologista, o paciente deverá ser encaminhado para realização do estadiamento oncológico em acordo com TNM para melhor registro e comparação de dados.

Os seguintes exames de estadiamento devem ser realizados:

Exame dermatológico; CT e / ou RNM de tórax, abdome e pelve; biópsia de áreas suspeitas.

Após o estadiamento, o radio-oncologista avaliará a indicação de braquiterapia com a fonte de Ru-106.

Definição do Volume Alvo

O volume tumoral clínico (CTV) é principalmente baseado em achados da ultra-sonografia (diâmetro e espessura da base do tumor).Uma margem de segurança de 1 - $2 \mathrm{~mm}$ do diâmetro de base para doença subclínica é adicionada em todas as direções, para garantir adequada cobertura em região com risco de disseminação microscópica ao longo da túnica ocular, principalmente a úvea e a esclera. Em algumas situações, podem ser observadas incertezas na delineação do tumor (por exemplo, no desenho exato da sombra do tumor durante a transiluminação) e / ou na localização da placa (por exemplo, nas posições dos pólos posteriores), que podem ser consideradas adicionando uma margem de segurança extra com volume tumoral planejado (PTV). O montante dessa margem de segurança deve ser determinado individualmente de acordo com a extensão de invasão subclínica. Nenhuma outra margem de segurança para a movimentação é dada, já que a placa é suturada firmemente na esclera externa. Considerações de margem de segurança devem ser especialmente consideradas se o tumor estiver localizado na vizinhança de estruturas críticas, como o disco óptico, a mácula ou o 
corpo ciliar. Em determinadas situações (melanoma amelanótico, configurações específicas de cogumelos) são necessários cuidados específicos na delimitação do tumor.

A espessura da CTV é determinada pela espessura do tumor. A espessura é geralmente avaliada por ecografia (B-scan) adicionado $1 \mathrm{~mm}$ para a esclera. A espessura é medida no ponto mais proeminente do tumor em forma de cúpula (ápice do tumor) com uma linha traçada para a úvea, perpendicular à base.

O volume total do tumor e as suas extensões microscópicas formam a base do volume alvo, pelo que a dose do tumor do ápice representa a dose alvo mínima (para as células tumorais do ápice). Em contraste, a camada uveal forma a base do tumor, a partir da origem e drenagem vascular uveal. Esta camada recebe uma dose significativamente mais elevada, que está próxima da dose em esclera (superfície). A dose alvo mínima e a dose superficial em esclera devem ser registadas. Como as estruturas críticas a serem preservadas (fóvea, disco óptico, coroide, retina) estão localizadas ao nível da base tumoral, estas doses são mais relevantes na avaliação da morbidade da braquiterapia.

\subsection{Procedimento de braquiterapia oftálmica com Ru-106}

Anteriormente ao início da aplicação, o paciente deve ser esclarecido sobre o tratamento e da necessidade de sua colaboração para o bom andamento dos procedimentos.

Antes do início da cirurgia deve-se verificar:

- A identidade do paciente;

- A prescrição na ficha de tratamento;

- O tempo de permanência da placa;

- Integridade da placa de Rutênio; 
- Modelo da placa a ser utilizada;

- Placa no container blindado;

No decorrer da cirurgia:

- Após o paciente estar anestesiado, o cirurgião irá verificar se os músculos oculares precisarão ser realocados caso interfiram na inserção da placa. Após uma transiluminação ocular é possível ver as sombras da lesão na esclera subjacente, deve ser dado de 2 a $3 \mathrm{~mm}$ de margem e colocar a placa falsa (dummy) verificando se toda a lesão foi coberta, verificar se a inserção e a sutura estão adequadas.

Retirada da dummy, e inserir a placa de Rutênio e fazer a fixação o mais rápido possível.

Monitorar os níveis de dose durante o procedimento.

Paciente ficará em quarto especial com medidas de radioproteção adotadas:

- Símbolo internacional de presença de radiação ionizante;

- Plano de ação para situação de emergência contendo a identificação dos responsáveis a serem acionados em situação de emergência e seus telefones para contato.

- O número e características das fontes de radiação utilizadas no tratamento devem estar disponíveis no prontuário do paciente.

Na retirada da fonte monitorar os níveis de dose no ambiente e nos IOE(s).

Esterilização das placas no contêiner e coloca-la na sala quente.

Registre os detalhes de tratamento na ficha do paciente (Anexo 3) não se esquecendo de incluir:
a. A data;
b. O tipo de placa utilizada;
c. O tempo total; 
d. A dose total para cada área alvo ou ponto de interesse (Ápice, esclera).

\subsection{Procedimento cirúrgico:}

$\mathrm{Na}$ inserção, a cirurgia dura por volta de 40 minutos, o paciente é sedado com anestesia geral, depois os cirurgiões oftálmicos iniciam o procedimento, com as seguintes etapas: Peritomia conjuntival, reparo dos músculos retos, desinserção do músculo reto do quadrante que está o tumor, localização e delimitação do tumor na esclera usando um transiluminador.

O tumor é localizado por iluminação transescleral e o GTV e ou o CTV são marcados com precisão na esclerótica sobreposta. Com base nessa marcação, que indica a borda externa da lesão, a placa adequada é escolhida, dando uma margem

de 1 a $2 \mathrm{~mm}$ das bordas e levando em conta os resultados do ultrassom. É usada a placa falsa (dummy) para verificar o posicionamento, após bem delimitado e localizado, a fonte é substituída e a placa de Rutênio-106 é suturada sobre a lesão com Mersilene 5-0 a conjuntiva é suturada com Vicryl 6-0, e feito curativo oclusivo com pomada de corticoide e antibiótico.

Ao encaminhar o aplicador para o oftalmologista que executa o procedimento cirúrgico, deve ter-se cuidado que a superfície de irradiação côncava do aplicador esteja sempre direcionada para material absorvente de radiação.

A retirada da fonte é mais rápida, por volta de 15 minutos, ao invés da anestesia geral, é realizado um bloqueio local, e os músculos são reinseridos.

O tempo de exposição da equipe com a fonte radioativa é no máximo 15 minutos por procedimento, entre inserção e retirada. 


\subsection{Análise dos resultados e seguimento:}

O seguimento é realizado a cada 3 meses durante os primeiros 2 anos e 6 meses até completar os 5 anos de intervalo de tratamento.

São realizados retinografia e ultrassom de olho, com a avaliação das dimensões da lesão. Também são avaliadas as complicações do tratamento, com atenção aos sintomas clínicos e função ocular. 


\section{RESULTADOS:}

A Tabela 1 mostra todos os 10 pacientes com melanoma tratados no setor nos primeiros 18 meses.

Tabela1: Pacientes tratados com Ru-106 em seguimento.

\begin{tabular}{|c|c|c|c|c|c|}
\hline PACIENTE & 1 & 2 & 3 & 4 & 5 \\
\hline DATA DO PROCEDIMENTO & $28 / 12 / 2015$ & $28 / 12 / 2015$ & $27 / 02 / 2016$ & $17 / 10 / 2016$ & $20 / 10 / 2016$ \\
\hline Idade & 71 & 66 & 49 & 74 & 49 \\
\hline Olho & Direito & Esquerdo & Esquerdo & Esquerdo & Direito \\
\hline Placa & COB (Notch) & CCB & COB (notch) & CCB & COB(Notch) \\
\hline Diâmetros Base Radial (mm) & 9,5 & 17,4 & 12,9 & 7,3 & 8,3 \\
\hline Ápice + Esclera (mm) & 2,6 & 5,6 & 3,2 & 3,3 & 4,1 \\
\hline Dose (Gy) & 89,5 & 82,5 & 85,4 & 85 & 90,7 \\
\hline Dose na Base (Gy) & 140 & 334,5 & 160,6 & 160,6 & 229,3 \\
\hline Tempo de Internação (horas) & 22 & 52,5 & 37,5 & 43,5 & 62,5 \\
\hline \hline PACIENTE & 6 & 7 & 8 & 9 & 10 \\
\hline DATA DO PROCEDIMENTO & $20 / 12 / 2016$ & $20 / 12 / 2016$ & $18 / 01 / 2017$ & $04 / 07 / 2017$ & $04 / 07 / 2017$ \\
\hline Idade & 38 & 80 & 38 & 74 & 76 \\
\hline Olho & Direito & Esquerdo & Esquerdo & Esquerdo & Esquerdo \\
\hline Placa & $\mathrm{CCB}$ & $\mathrm{COB}$ (notch) & $\mathrm{CCB}$ & $\mathrm{COB}(\mathrm{notch})$ & $\mathrm{CCB}$ \\
\hline Diâmetros Base Radial (mm) & 8 & 14 & ---- & 12 & 11,4 \\
\hline Ápice + Esclera (mm) & 4,2 & 3,5 & 1 & 6,1 & 6,7 \\
\hline Dose (Gy) & 85,9 & 85 & 87,8 & 81,2 & 74,7 \\
\hline Dose na Base (Gy) & 214,4 & 174,6 & 96,3 & 501 & 516 \\
\hline Tempo de Internação (horas) & 65,4 & 53,2 & 28,2 & 166 & 175,3 \\
\hline
\end{tabular}

Foram irradiados 11 pacientes, sendo 10 pacientes com diagnóstico de melanoma de coroide e um paciente com hemangioma. O paciente de hemangioma recebeu uma dose de 39,3 Gy no ápice + esclera (5,5 mm) e 166,5 Gy na base.

Para os melanomas, as doses no ápice + esclera variaram de 90,7 Gy até 74,7 GY, com dose média de 84,8 Gy. Já as doses na base variaram de 96,3 Gy até 516 Gy, com dose média de 252,7 Gy. As dimensões ápice + esclera consideradas variaram de $1,0 \mathrm{~mm}$ até $6,7 \mathrm{~mm}$, com valor médio de $4,0 \mathrm{~mm}$. As dimensões médias da base foi $11,2 \mathrm{~mm}(7,3-17,4)$.

Os tempos de internação mínimos e máximos foram de 22 horas e 175 horas respectivamente. 
Metade dos pacientes, 5 deles usaram a placa do tipo COB (notch), para lesões próximas do nervo óptico e a outros 5 pacientes utilizaram a placa do tipo CCB.

A idade média dos pacientes tratados foram 61,5 anos (entre 38 e 80 anos).

O paciente número 8 realizou ressecção tumoral antes da braquiterapia, foi considerada para esse caso a profundidade de 1,0 $\mathrm{mm}$.

Foram analisados os exames de ultrassom dos pacientes para comparação. $\mathrm{Na}$ Tabela 2 tem os resultados da regressão das lesões dos primeiros cinco pacientes após o procedimento da Braquiterapia.

Para um seguimento médio de 12 meses, as lesões dos primeiros três pacientes regrediram em média $28 \%$ e $12 \%$ nas dimensões do ápice e base respectivamente.

Para os outros 2 pacientes com seguimento médio de 5,5 meses, houve uma regressão das lesões em média 8\% no ápice e 14\% na base.

Tabela 2: Variação das dimensões tumorais dos primeiros 5 pacientes durante um intervalo de tempo

\begin{tabular}{|c|c|r|r|r|r|}
\hline & \multicolumn{2}{|l|}{} & \multicolumn{2}{l}{ Seguimento } \\
& \multicolumn{2}{|l|}{ Pré Braquiterapia } & \multicolumn{2}{l|}{ Pós Braquiterapia } & (meses) \\
\hline Paciente & \multicolumn{2}{|c|}{ Ápice (mm) } & Base(mm) & Ápice (mm) & Base(mm) \\
\hline 1 & 2,6 & 9,5 & 1,8 & 8,8 & 12 \\
\hline 2 & 5,6 & 17,4 & 3,8 & 13,8 & 13 \\
\hline 3 & 3,2 & 12,9 & 2,5 & 11,7 & 5 \\
\hline 4 & 2,3 & 7,3 & 2,1 & 5,7 & 6 \\
\hline 5 & 4,1 & 8,3 & 3,8 & 7,8 & 13 \\
\hline
\end{tabular}


Nas imagens de ultrassom abaixo, figuras (3 e 4) é possível comparar a regressão da lesão do paciente 2, figura 3, antes da Braquiterapia, e a figura 4, 13 meses após o procedimento.

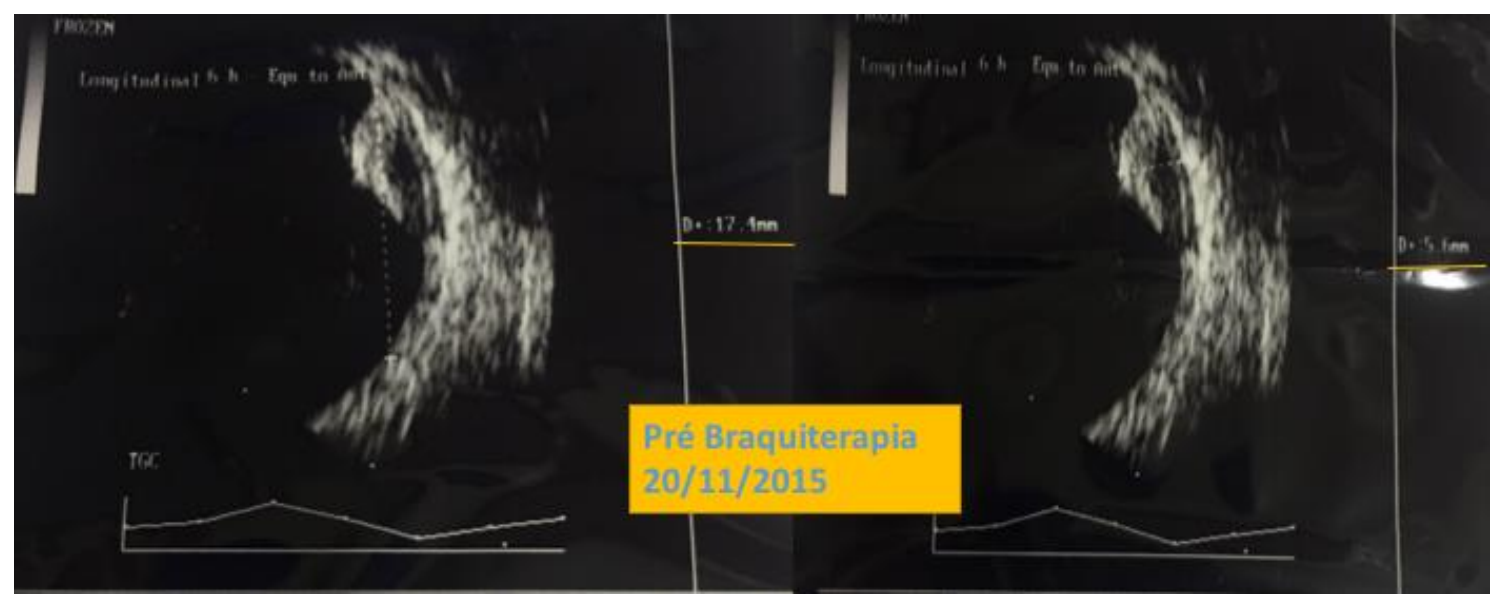

Figura 3: Ultrassom com as medidas do tumor do paciente 2 antes da Braquiterapia com Ru-106.

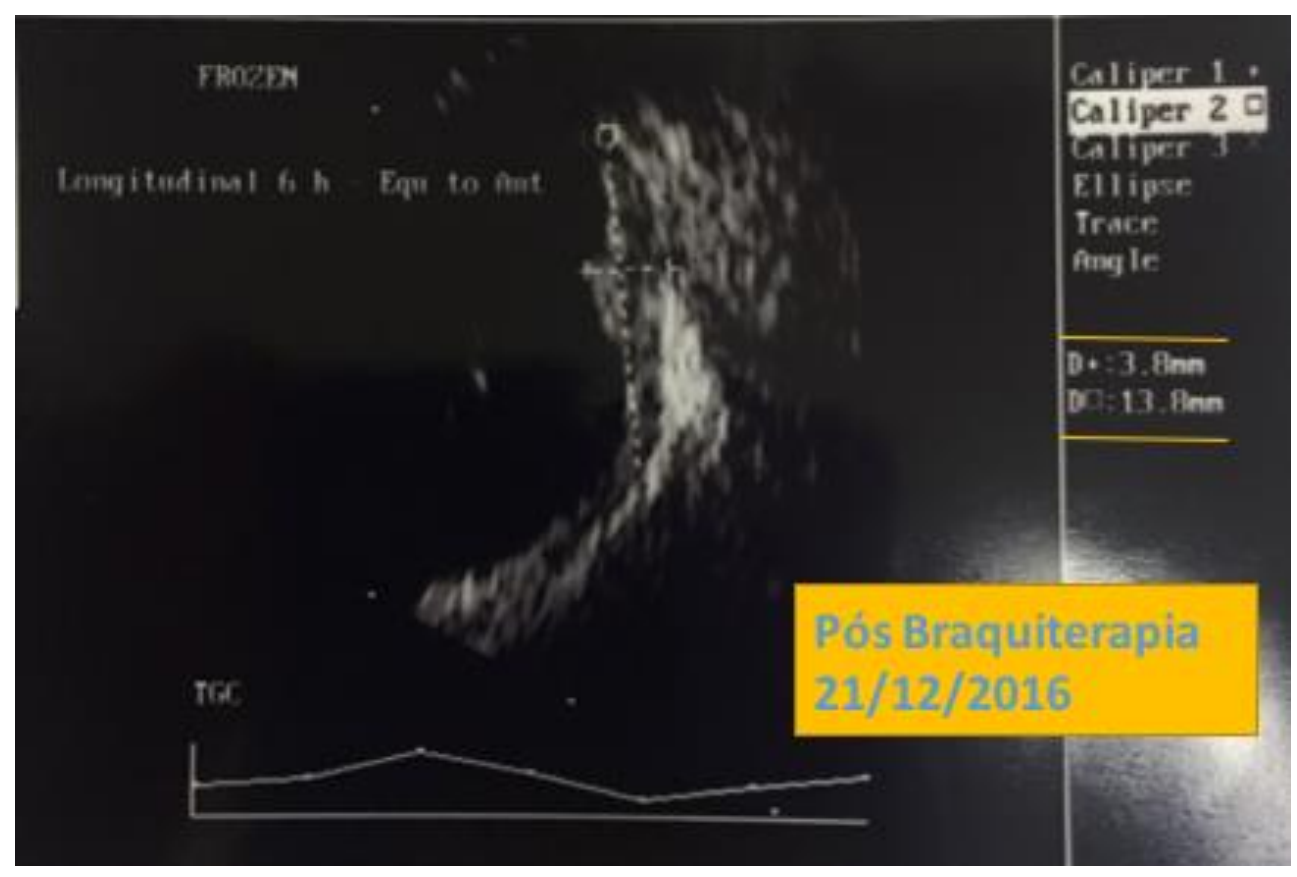

Figura 4: Ultrassom com as medidas do tumor do paciente 213 meses após da Braquiterapia com Ru-106.

A figura 5 mostra as dimensões do tumor do paciente 1, Ápice 2,6 mm e base 9,5 mm antes da Braquiterapia. Já na figura 6 as dimensões são de 1,8 mm no ápice e 8,8mm na base após 12 meses. 


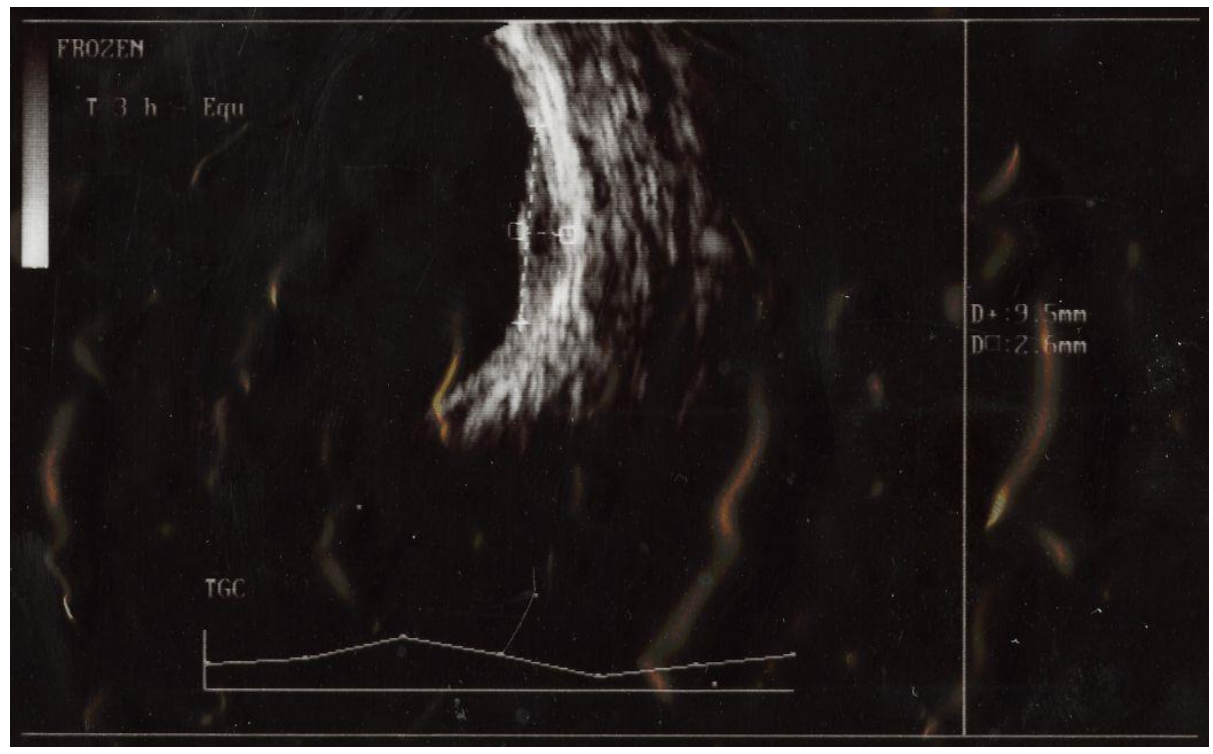

Figura 5: Ultrassom com as medidas do tumor do paciente 1 antes da Braquiterapia com Ru-106.

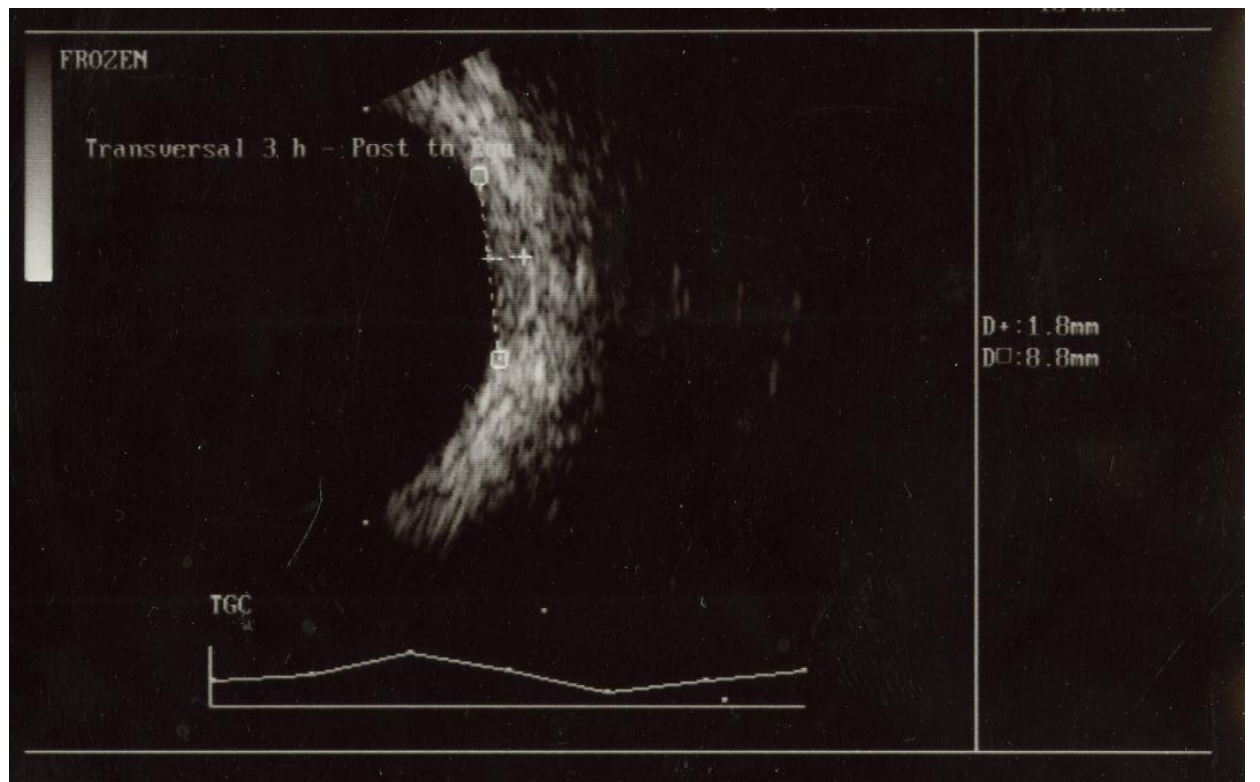

Figura 6: Ultrassom com as medidas do tumor do paciente 112 meses após da Braquiterapia com Ru-106.

Pelo exame de retinografia abaixo (Figura 7) do paciente 2, é possível observar a regressão da lesão, á esquerda antes do procedimento e a imagem da direita 11 meses após. 


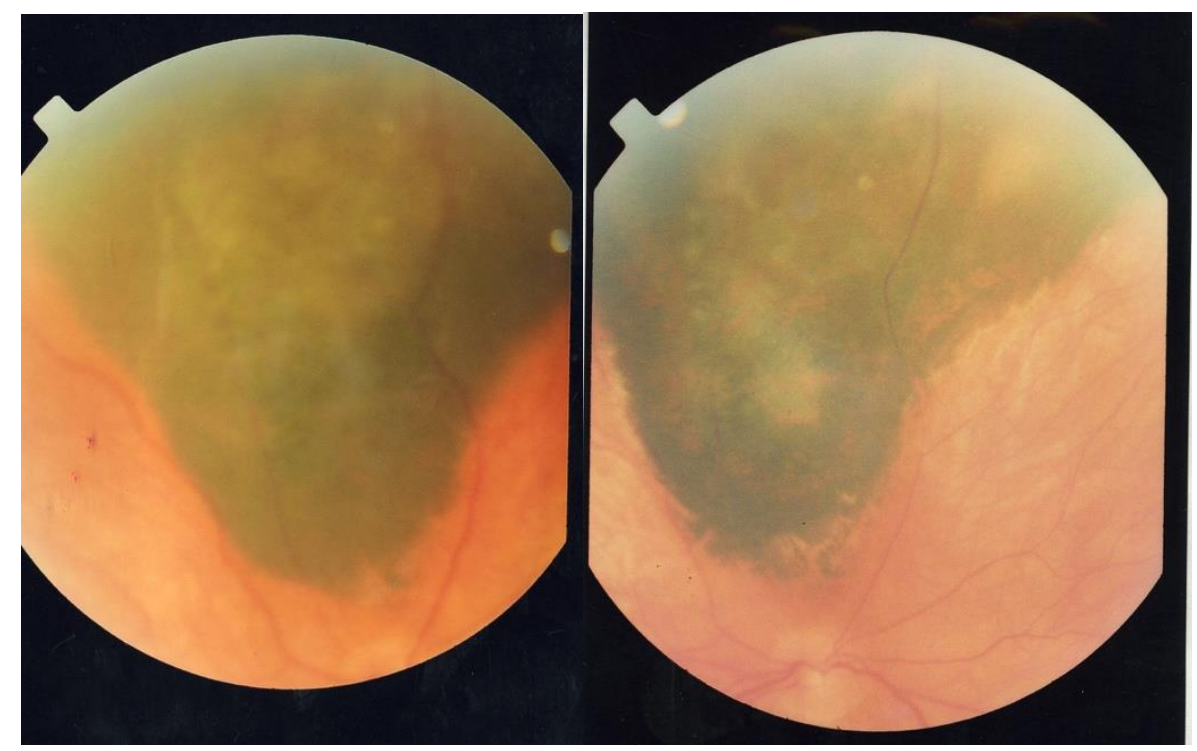

Figura 7: Á esquerda retinografia do paciente 2 antes da Braquiterapia, e à direita 11 meses de seguimento.

Para o paciente 1, a Figura 8 corresponde ao exame de retinografia antes do procedimento e a Figura 9 após10 meses após o procedimento.

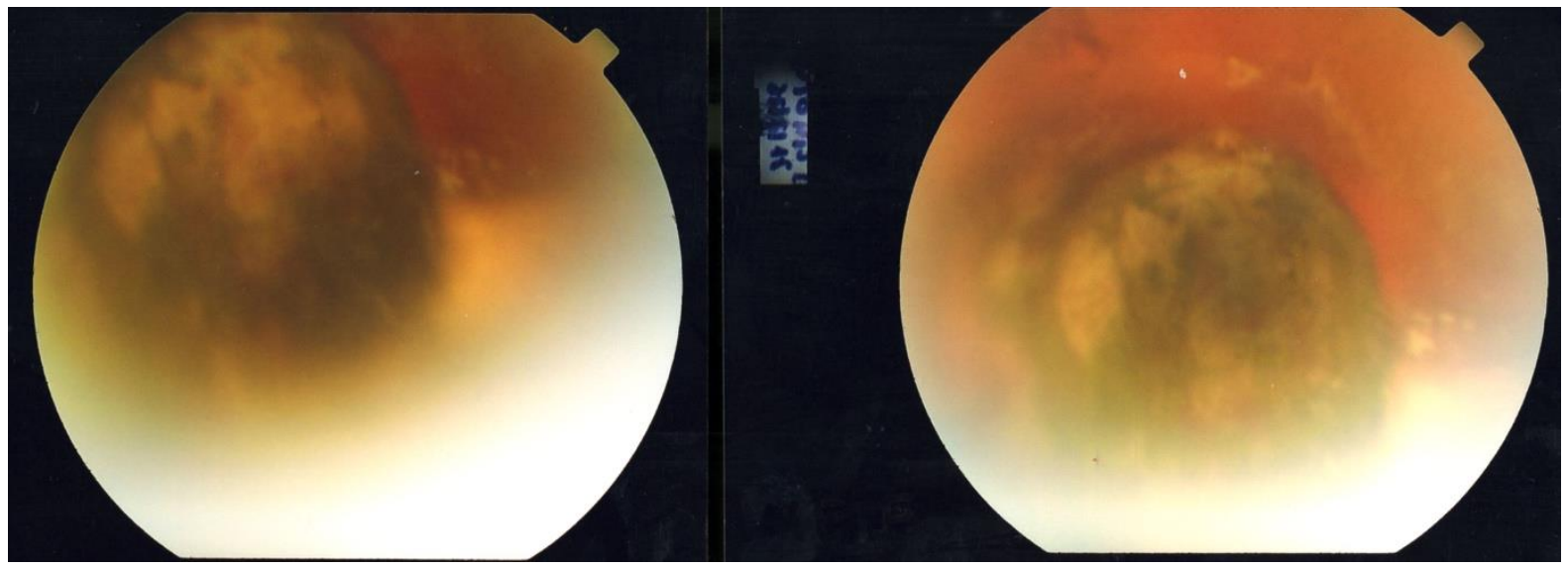

Figura 8: Retinografia do Paciente 1 antes da Braquiterapia com Ru-106. 


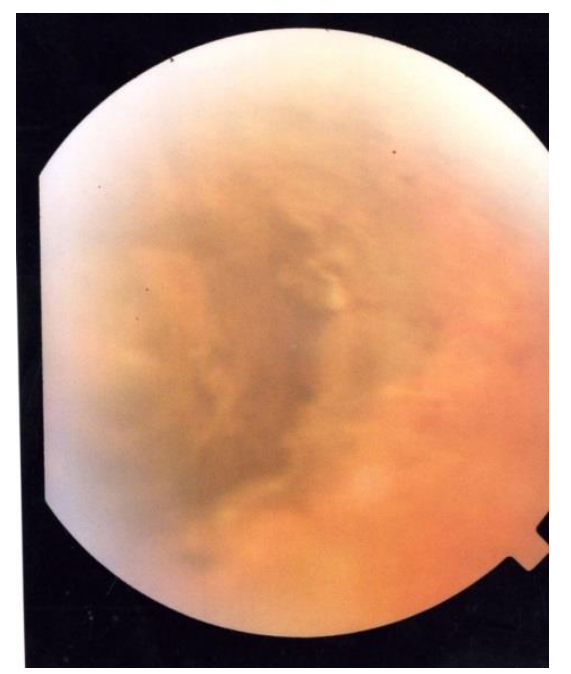

Figura 9: Retinografia do Paciente ,1 10 meses após a Braquiterapia com Ru-106. 


\section{DISCUSSÃO:}

O principal objetivo no início desse trabalho era elaborar um protocolo com informações relevantes e necessárias para encorajar a criação de mais centros de Braquiterapia Oftálmica no Brasil. No entanto, com após a consolidação do protocolo, foi possível estender para outros objetivos, como analisar as informações dos pacientes submetidos ao tratamento, como doses, dimensões das lesões, e, analisar o seguimento desses pacientes após o procedimento.

Sobre o processo de implementação, a etapa que envolve a submissão do plano de radioproteção para a CNEN para obtenção da licença de importação e uso da fonte, é importante destacar que todas as informações necessárias, desde a finalidade da fonte, características, funções dos profissionais envolvidos e a política de radioproteção devem ser adotadas no intuito de garantir a qualidade e a segurança do tratamento, informações essas que se encontram bem detalhadas nesse trabalho.

Em concomitância com essa etapa foi necessário a criação de protocolos clínicos envolvendo principalmente a Radioterapia e a Onco-Oftalmologia. Nesses protocolos foi importante estabelecer os critérios de inclusão e exclusão dos casos, doses de prescrição no ápice e doses de tolerância adotadas para esclera e outras estruturas, as responsabilidades de cada profissional, a ficha de encaminhamento da oftalmologia para a Radioterapia (Anexo 2), elaboração de uma ficha técnica de tratamento, com as informações mais relevantes, conforme Anexo 3.

O uso de placas de Rutênio-106 é o tratamento recomendado na Europa para o melanoma uveal de tamanho médio desde 1960, que comparado as placas de I125 consegue administrar menor dose nas estruturas normais do olho, como disco 
óptico, mácula e cristalino. No entanto devido ao seu alto gradiente de dose, em tumores maiores a dose no ápice pode não atingir a dose recomendada de 85 Gy $^{12,13,14}$. Alguns autores acreditam que para tumores maiores de $7 \mathrm{~mm}$, a alta dose na esclera pode ser um problema ${ }^{2,15}$. Em contraste, existem diversas outras publicações que evidenciam resultados clínicos favoráveis e até mesmo a regressão completa para tumores de grandes volume ${ }^{14,16}$.

Os resultados para os 10 pacientes com diagnóstico de melanoma uveal tratados com braquiterapia oftálmica, com dose média no ápice de 84 Gy, e espessura média de 4,0 mm $(1,0-6,7)$ estão em concordância com as recomendações de tratamento sugeridas em diferentes estudos clínicos que acessaram tal informação ${ }^{12,13}$.

Os estudos analisaram um grande número de pacientes com seguimento de 5 a 10 anos, avaliando principalmente a taxa de sobrevida, metástases, proporção de uma enucleação após o tratamento e deterioração da acuidade visual ${ }^{2,13-16}$. Apesar de algumas variações os resultados são comparáveis e mostram que a braquiterapia com Rutênio-106 possui adequadas taxas de controle tumoral, preservação do olho e suas funções.

Damato et al. $2005^{2}$, que analisou 458 pacientes tratados com Rutênio-106, seguimento de 47 meses, espessura média de $3,2 \mathrm{~mm}(0.7-7,0)$, diâmetro basal médio de 10,6 mm (5-16,6) e dose no ápice média de 80 Gy, com controle local de $97,9 \%$ em 5 anos.

Em nosso estudo, apesar do pouco seguimento, máximo de 13 meses, podemos comparar os resultados com essa publicação, pois os perfis dos pacientes são semelhantes, espessura média de 4,0 mm (1,0-6,7), diâmetro basal médio de $11,2 \mathrm{~mm}(7,3-17,4)$ e dose no ápice média de 84 Gy. 
Devido ao alto valor das placas aliado à baixa casuística, é inviável adquirir placas de Rutênio-106 de diferentes tamanhos, as aquisições dos dois tipos de placas foram suficientes para realizar todos os casos no serviço.

A Tabela 3, apresenta uma relação de diferentes radionuclídeos e respectivo controle local e à distância, sem diferença significativa entre o radionuclídeo utilizado. 
Tabela 3: Estudos realizados entre 1987 e 2009 comparando do radioisótopo utilizado, dose e controle localt .

\begin{tabular}{|c|c|c|c|c|c|c|c|c|c|c|c|c|}
\hline & & & & $\begin{array}{c}\text { Follow- } \\
\text { up }\end{array}$ & Thickness & $\begin{array}{c}\text { Basal } \\
\text { diameter }\end{array}$ & $\begin{array}{c}\text { Radiation } \\
\text { dose }\end{array}$ & $\begin{array}{c}\text { Local } \\
\text { control }\end{array}$ & $\begin{array}{c}\text { Local } \\
\text { control }\end{array}$ & Metastasis & Metastasis & $\begin{array}{l}\text { Visual } \\
\text { acuity }\end{array}$ \\
\hline Author & Year & $\begin{array}{c}\text { Patients } \\
\text { No. }\end{array}$ & Radionuclide & $\begin{array}{c}\text { Mean or } \\
\text { median, } \\
\text { mo }\end{array}$ & $\begin{array}{c}\text { Mean or } \\
\text { median (range) }\end{array}$ & $\begin{array}{c}\text { Mean or } \\
\text { median } \\
\text { (range) }\end{array}$ & $\begin{array}{l}\text { Apex, } \\
\text { mean }\end{array}$ & $\begin{array}{c}\text { Overall, } \\
\%\end{array}$ & $5 y$ & Overall & $5 y$ & $\begin{array}{c}\text { Final } \\
\%, \\
>20 / 200\end{array}$ \\
\hline Lommatzsch $^{13}$ & 1987 & 309 & ${ }^{106} \mathrm{Ru}$ & 80 & $3.7(1.2-11.8)$ & $9.7(4.5-21.5)$ & 100 & 69.9 & 84 & 12.9 & NA & NA \\
\hline Quivey et al. & 1996 & 239 & ${ }^{125} \mathrm{I}$ & 36 & $5.5(1.9-11.0)$ & $10.9(4-18)$ & 70 & 91.7 & 82 & 7.5 & 12 & NA \\
\hline Fontenesi et al. & 1993 & 144 & ${ }^{125} \mathrm{I}$ & 46 & $\begin{array}{l}\text { Small, } n=15 ; \\
\text { medium, } n=84 ; \\
\text { large, } n=45\end{array}$ & $\mathrm{NA}$ & 75 & 97.7 & 94.4 & 2.7 & 2 & 71.3 \\
\hline Seregard et al. & 1997 & 266 & ${ }^{106} \mathrm{Ru}$ & 43 & $4.4(1.0-13.1)$ & $10.0(3-23)$ & 100 & 83 & 82 & 11 & 14 & $\mathrm{NA}$ \\
\hline $\mathrm{COMS}^{3}$ & 2006 & 657 & ${ }^{125} \mathrm{I}$ & 96 & $4.8(2.5-10.0)$ & $\begin{array}{c}11.4 \text { (up to } \\
16 \text { ) }\end{array}$ & 85 & $\mathrm{NA}$ & NA & 9 & 9 & 63 \\
\hline Bechrakis et al. & 2002 & 152 & ${ }^{125} \mathrm{I}$ & 30.1 & $9.0 \pm 1.1$ & $14.6 \pm 2.4$ & $98 \pm 18$ & 88.8 & NA & 11.1 & NA & 5.6 \\
\hline Shields et al. ${ }^{6}$ & 2002 & 354 & ${ }^{125} \mathrm{I}$ & 60 & $9.0(9.8-16)$ & $14.0(5-21)$ & 80 & 91 & 91 & 24 & 24 & 43 \\
\hline Puusaari et al. & 2003 & 97 & ${ }^{125} \mathrm{I}$ & 43.2 & $10.7(4.5-16.8)$ & $16.1(7.3-25)$ & 87 & 94.8 & 94 & 28.9 & 35 & $\begin{array}{l}42 \text { at } \\
1 \text { year }\end{array}$ \\
\hline Damato et $a l .^{2}$ & 2005 & 458 & ${ }^{106} \mathrm{Ru}$ & 47 & $3.2(0.7-7.0)$ & $10.6(5-16.6)$ & 80 & 97 & 97.9 & 8.1 & NA & 57 \\
\hline Finger et al. & 2009 & 400 & ${ }^{103} \mathrm{Pd}$ & 51 & $3.8(1.5-12.3)$ & $10.5(5-19.9)$ & 73 & 97 & NA & 6 & 7.3 & 79 \\
\hline Mean & 2000 & 308 & & 53.2 & & & 84.8 & 90.1 & 89.3 & 12.2 & 14.8 & 53.2 \\
\hline Median & 2002 & 354 & & 46.5 & & & 82.5 & 91.7 & 91 & 10 & 12 & 57 \\
\hline
\end{tabular}

$\mathrm{NA}=$ not available; $\mathrm{COMS}=$ Collaborative Ocular Melanoma Study.Tumor measurements are expressed in millimeters, follow-up in months, patients' number in number of patients, $\%<20 / 200$ in those with better than 20/200 vision. 
O serviço de Braquiterapia Oftálmica é uma área multidisciplinar, envolvendo Oncologia, Radioterapia, Oftalmologia Clínica e Cirúrgica, enfermagem, sendo necessário uma adequada estrutura física e profissionais altamente especializados, fatores relacionados a baixa quantidade de serviços no Brasil que realizam esse procedimento. Aliado a isso, ainda temos a baixa incidência, o que desmotiva a implementação da técnica, além da inexistência desse procedimento no rol da Agência Nacional de Saúde Suplementar (ANS) e do Sistema Único de Saúde (SUS). Como já mencionado, os gastos para aquisição das fontes são elevados, inviabilizando sobremaneira a implementação de um serviço em um Hospital Geral. Foram pelo menos oito anos desde as primeiras conversas com a direção até o tratamento do primeiro paciente no serviço.

É necessária uma boa integração de todos os membros da equipe para organização e êxito dos tratamentos. Por isso é de fundamental importância desenvolver protocolos e fichas técnicas para auxiliar desde o encaminhamento do paciente da Oftalmologia para a Radioterapia com todas informações necessárias para o estadiamento e definição das dimensões do tumor. Assim é possível o radiooncologista prescrever a dose, o físico calcular no tempo necessário e conciliar a melhor logística para inserção e retirada da fonte com os cirurgiões.

Durante o início do serviço e dos primeiros casos deparamos com algumas dificuldades. Entre elas, qual seria a melhor forma de fazer o encaminhamento dos pacientes diagnosticados para a Braquiterapia. Esse problema foi solucionado criando a ficha de encaminhamento (Anexo 2) com as informações que devem ser preenchidas por eles para confirmar a indicação, estabelecer as doses e calcular o 
tempo de tratamento, e a partir da duração estabelecer em comum acordo quais os melhores dias e horários para inserção e retirada da fonte.

Outra consideração que merece destaque é o seguimento desses pacientes, primeiro pela dificuldade de alguns retornarem ao Hospital por serem de cidades distantes, e quais seriam os exames e procedimentos com sua devida periodicidade que deverão ser realizados, para no futuro termos informações suficientes para a avaliação dos resultados. Este seguimento é contínuo e deveremos atualizar os dados dos resultados para constante atualização do protocolo de tratamento. 


\section{CONCLUSÃO:}

Os resultados dos 11 pacientes tratados são encorajadores com a significativa redução das lesões. Visto que a resposta clínica da redução tumoral é lenta, estes pacientes devem ser seguidos por maior período de tempo.

No caso de um Hospital que possui a estrutura física de Radioterapia, Oftalmologia, centro cirúrgico, internação e os devidos profissionais qualificados, o passo seguinte é a autorização para CNEN de importação e utilização a fonte. Como foi descrito é necessário a elaboração de um plano de radioproteção contendo todas as informações do elemento radioativo, das funções dos profissionais, estrutura física e procedimentos de proteção radiológica a serem adotados. Para uma boa estruturação do serviço é preciso desenvolver os protocolos clínicos, fichas técnicas e de encaminhamento. Este trabalho mostra as informações necessárias que devem ser contidas tanto no plano de radioproteção como as informações necessárias para estabelecer os protocolos de um novo serviço. 


\section{BIBLIOGRAFIA:}

1. Nehemy M. Oftalmologia na parte clínica.Belo Horizonte: Folium,2015. 398p

2. Damato B, Patel I, Campbell IR, Mayles HM, Errington RD. Visual acuity after Ruthenium106 brachytherapy of choroidal melanomas. Int J Radiat Oncol. 2005;63(2):392-400.

3. Collaborative Ocular Melanoma Study Group. The COMS Randomized Trial of lodine 125 Brachytherapy for Choroidal Melanoma. Arch Ophthalmol. 2006;124(12):1684.

4. American Brachytherapy Society - Ophthalmic Oncology Task Force. Electronic address: paulfinger@eyecancer.com, ABS - OOTF Committee. The American Brachytherapy Society consensus guidelines for plaque brachytherapy of uveal melanoma and retinoblastoma. Brachytherapy. $2014 ; 13(1): 1-14$.

5. Sakamoto T, Sakamoto M, Yoshikawa $\mathrm{H}$, et al. Histologic Findings and Prognosis of Uveal Malignant Melanoma in Japanese Patients. $A m J$ Ophthalmol. 1996;121(3):276-283.

6. Shields CL, Furuta M, Thangappan A, et al. Metastasis of Uveal Melanoma Millimeter-by-Millimeter in 8033 Consecutive Eyes. Arch Ophthalmol. $2009 ; 127(8): 989$.

7. Coupland SE, Damato BE. Molecular Analysis of Uveal Melanoma. Ophthalmology. 2013;120(7):e50.

8. Chao AN, Shields CL, Shields JA, Krema H. Plaque Radiotherapy For Choroidal Hemangioma With Total Retinal Detachment And Iris Neovascularization. Retina. 2001;21(6):682-684. 
9. Damato BE, Coupland SE. Ocular melanoma. Saudi J Ophthalmol Off J Saudi Ophthalmol Soc. 2012;26(2):137-144.

10. Hall EJ, Giaccia AJ. Radiobiology for the Radiologist.

11. Wambersie A, Chassagne D, Dutreix A, et al. Quality assurance in brachytherapy: the role of the ICRU in achieving uniformity in dose and volume specification for reporting. Rays. 1996;21(4):541-558.

12. Nag S, Quivey JM, Earle JD, Followill D, Fontanesi J, Finger PT. The American Brachytherapy Society recommendations for brachytherapy of uveal melanomas. Int J Radiat Oncol. 2003;56(2):544-555.

13. Lommatzsch P. beta-Irradiation of retinoblastoma with $106 \mathrm{Ru} / 106 \mathrm{Rh}$ applicators. Mod Probl Ophthalmol. 1977;18:128-136.

14. Naseripour M, Jaberi R, Sedaghat A, et al. Ruthenium-106 brachytherapy for thick uveal melanoma: reappraisal of apex and base dose radiation and dose rate. J Contemp Brachytherapy. 2016;8(1):66-73.

15. Bergman L, Nilsson B, Lundell G, Lundell M, Seregard S. Ruthenium Brachytherapy for Uveal Melanoma, 1979-2003Survival and Functional Outcomes in the Swedish Population. Ophthalmology. 2005;112(5):834-840.

16. Kaiserman N, Kaiserman I, Hendler K, Frenkel S, Pe'er J. Ruthenium-106 plaque brachytherapy for thick posterior uveal melanomas. $\mathrm{Br} J$ Ophthalmol. 2009;93(9):1167-1171.

17. Astrahan MA. A patch source model for treatment planning of ruthenium ophthalmic applicators. Med Phys. 2003;30(6):1219-1228.

18. Soares CG, Vynckier S, Järvinen $\mathrm{H}$, et al. Dosimetry of beta-ray ophthalmic applicators: Comparison of different measurement methods. Med Phys. $2001 ; 28(7): 1373-1384$. 
19. Soares CG, Mclaughlin WL. Measurement of Radial Dose Distributions Around Small Beta-Particle Emitters Using High-Resolution Radiochromic Foil Dosimetry. 1993;47. 


\section{ANEXO 1: PROTOCOLO DE BRAQUITERAPIA OFTALMICA COM}

\section{RU-106:}

A implantação da braquiterapia oftálmica exige uma sequência de processos e etapas, além da formação e capacitação da equipe médica, física e técnica, que é fundamental para a garantia da qualidade da entrega da dose. Para os procedimentos de braquiterapia oftálmica, é necessário a aquisição da placa radioativa, obter a autorização de compra e posteriormente a importação, sendo necessário a submissão de um plano de radioproteção à Comissão Nacional De Energia Nuclear (CNEN), descrevendo o elemento radioativo, finalidade, funções dos profissionais envolvidos e procedimentos de segurança.

\subsection{Característica e Descrição técnica:}

a. $\quad$ Placa de Rutênio-106

A placa de Rutênio-106, figura 10, tem sido utilizada há mais de 30 anos por oftalmologistas para tratamento de tumores oculares. Devido a suas características técnicas aliada à sua meia vida longa, 373,6 dias, pode ser usada inúmeras vezes num período de um a dois anos. Não requer montagem, visto tratar-se de uma peça inteiriça, nem risco de perder fontes durante o procedimento, apenas esterilização após o uso. 


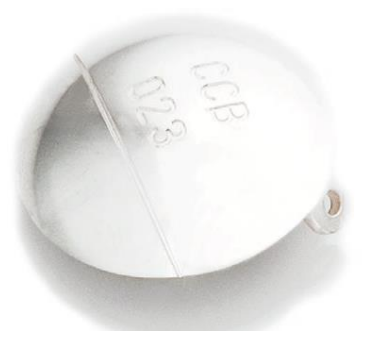

Figura 10: Placa de Rutênio-106 do tipo CCB. (Fonte: Eckert \& Ziegler BEBIG GmbH).

O núcleo radioativo do aplicador é uma lâmina coberta com Rutênio-106 que decai com meia vida de 373,6 dias em Ródio-106 até Paládio, elemento estável. Esse núcleo é encapsulado entre camadas de prata de 0,1 mm, que absorve aproximadamente 95\% da radiação beta de baixa energia (0,039 MeV) (figura 11).

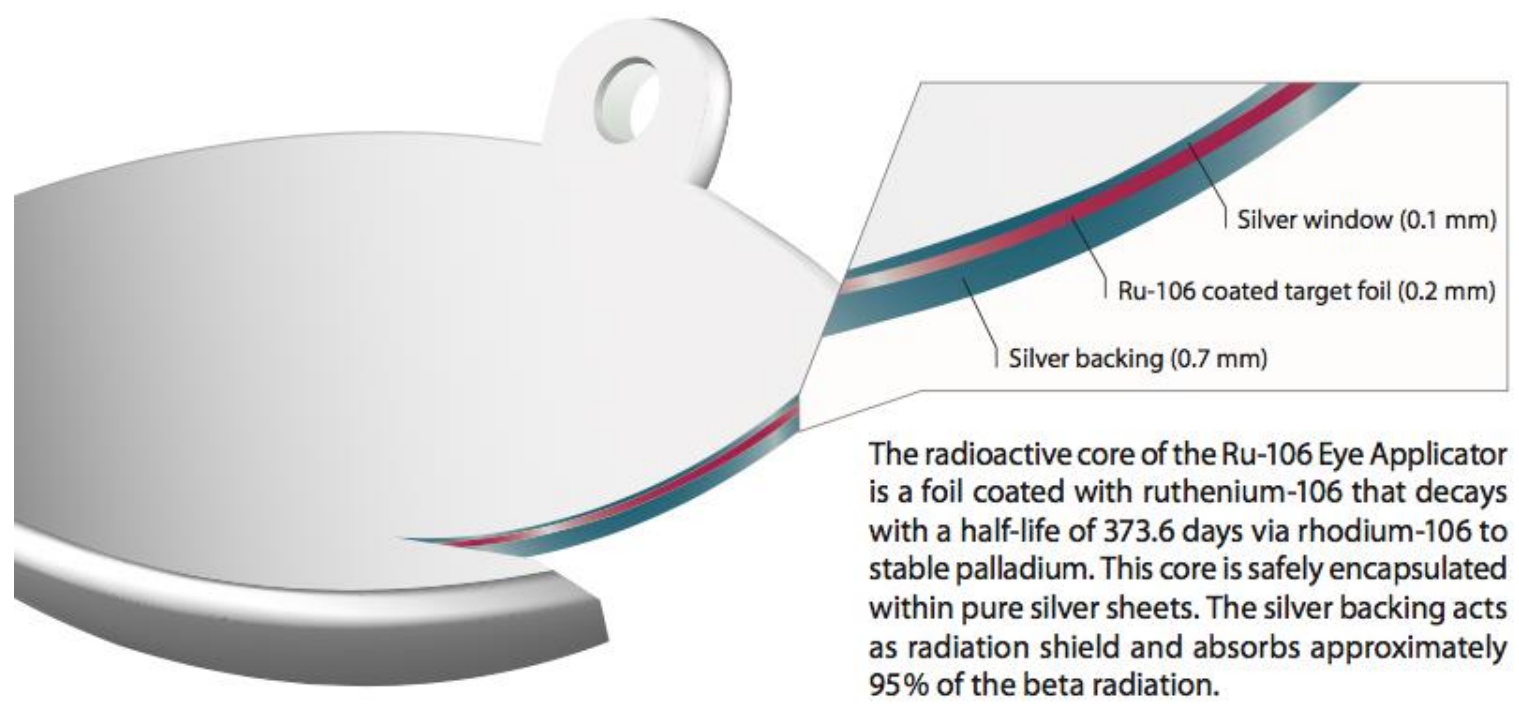

Figura 11: Design da Placa de Rutênio 106, com a composição otimizada para uma melhor distribuição de dose e blindagem.(Fonte: Eckert \& Ziegler BEBIG $\mathrm{GmbH}$ ).

O decaimento do ródio-106 promove liberação de energia de 3.542 keV. Esta energia é distribuída entre a partícula beta e o anti-neutrino emitido no decaimento, tornando o espectro beta contínuo. A energia da partícula beta do ródio-106 é utilizada no processo terapêutico,uma vez que a partícula beta emitida pelo rutênio é pouco penetrante e não contribui para a deposição de dose no tecido tumoral. 0 
período de meia-vida de uma fonte de ródio-106 é de 29,8 segundos, e por issouma fonte de rutênio/ródio-106 assume o período de meia-vida de 373,6 dias ${ }^{17}$.

A radiação beta emitida pelo $\mathrm{Ru}-106 / \mathrm{Rh}-106$ tem uma energia máxima de 3,54 $\mathrm{MeV}$ que deposita quase toda sua energia próxima a região a ser tratada, sendo ideal para tratamento de tumores com espessura em torno de $6 \mathrm{~mm}$. A radiação gama emitida pelo Rh-106 contribui em torno de $1 \%$ com a dose total, sendo praticamente desprezível. Junto com a fonte adquirida, acompanha uma tabela com a variação da taxa de dose pela profundidade (figura 12), que será utilizada para o cálculo de dose, corrigido pelo decaimento da data do procedimento.

Existem no mercado 16 formatos de placas com diferentes dimensões para um tratamento mais conformado. Os tipos de placas podem ser vistos na figura 13.
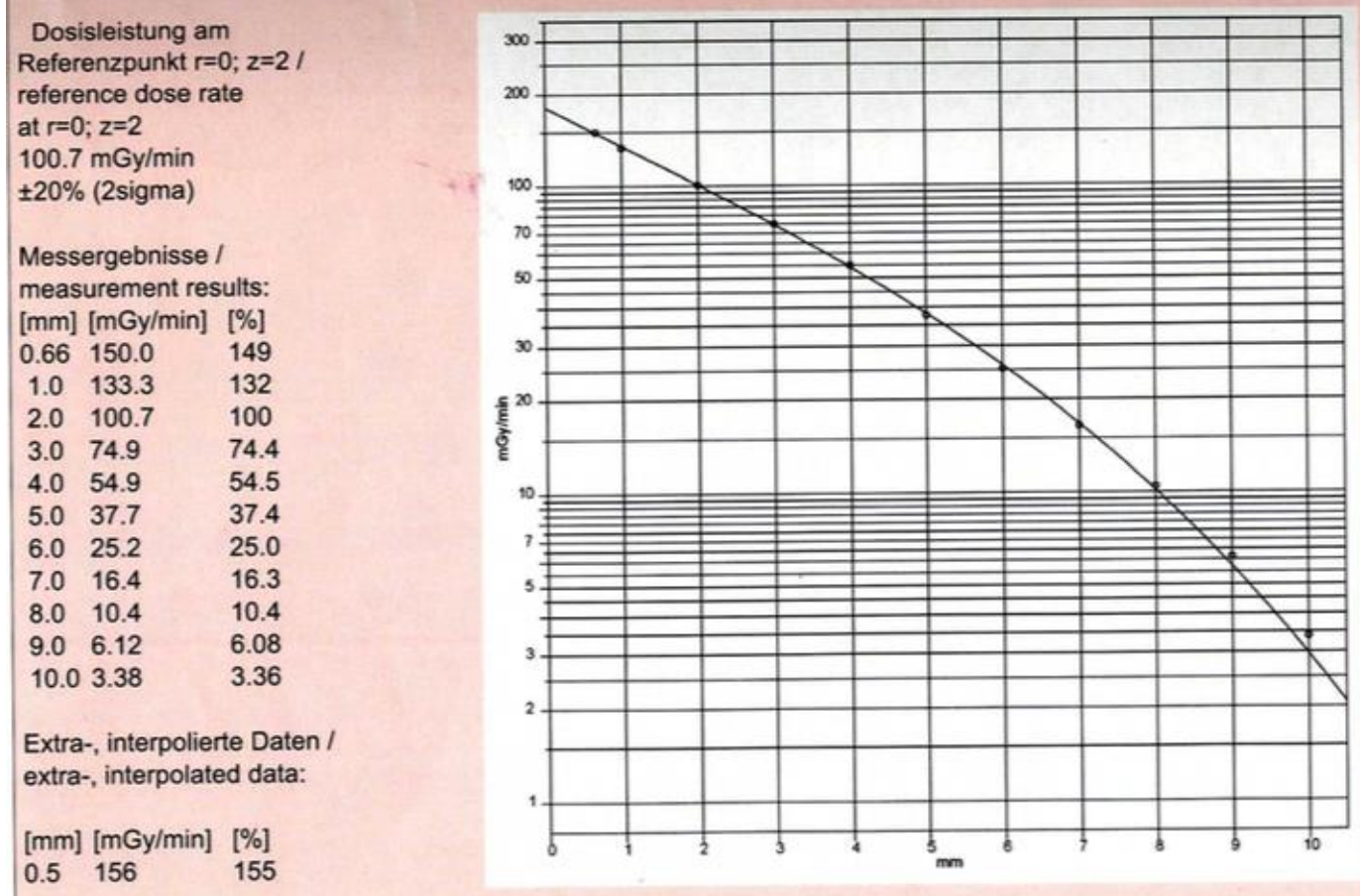

Figura 12: Tabela da variação da taxa de dose da placa de Rutênio -106 com a profundidade. 


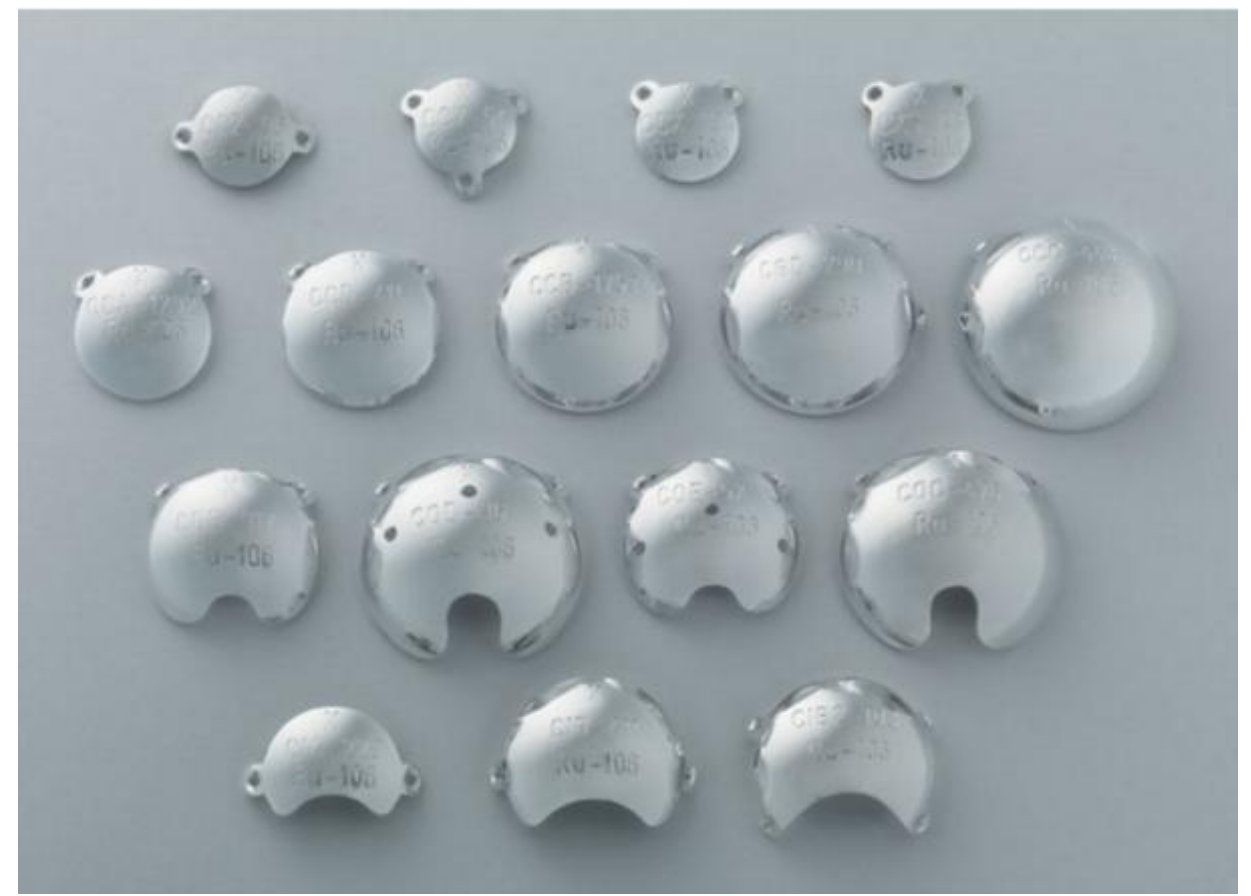

Figura 13: 16 diferentes tipos de placas de Rutênio -106. (Fonte: Eckert \& Ziegler BEBIG GmbH).

\section{b. Do material radioativo}

Radionuclídeo: ${ }^{106} \mathrm{Ru}\left(\mathrm{T}_{1 / 2}=373,6\right.$ dias $)$;

Atividade nominal: $19 \mathrm{Mbq}(0,5 \mathrm{mCi})$;

Aplicação: Braquiterapia Oftalmológica de Baixa Taxa de Dose (LDR), Fornecedor: BEBIG

Energias: Energia Máxima das radiações beta: 3,54 MeV

Na figura 14 temos o esquema do decaimento do Rutênio até Paládio.

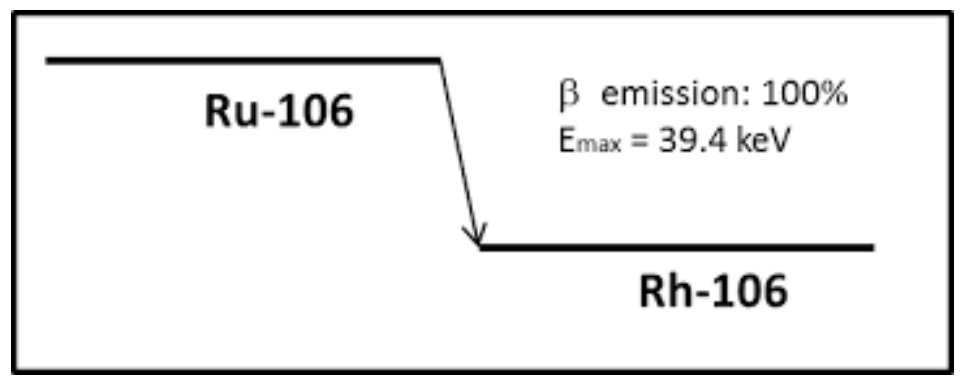




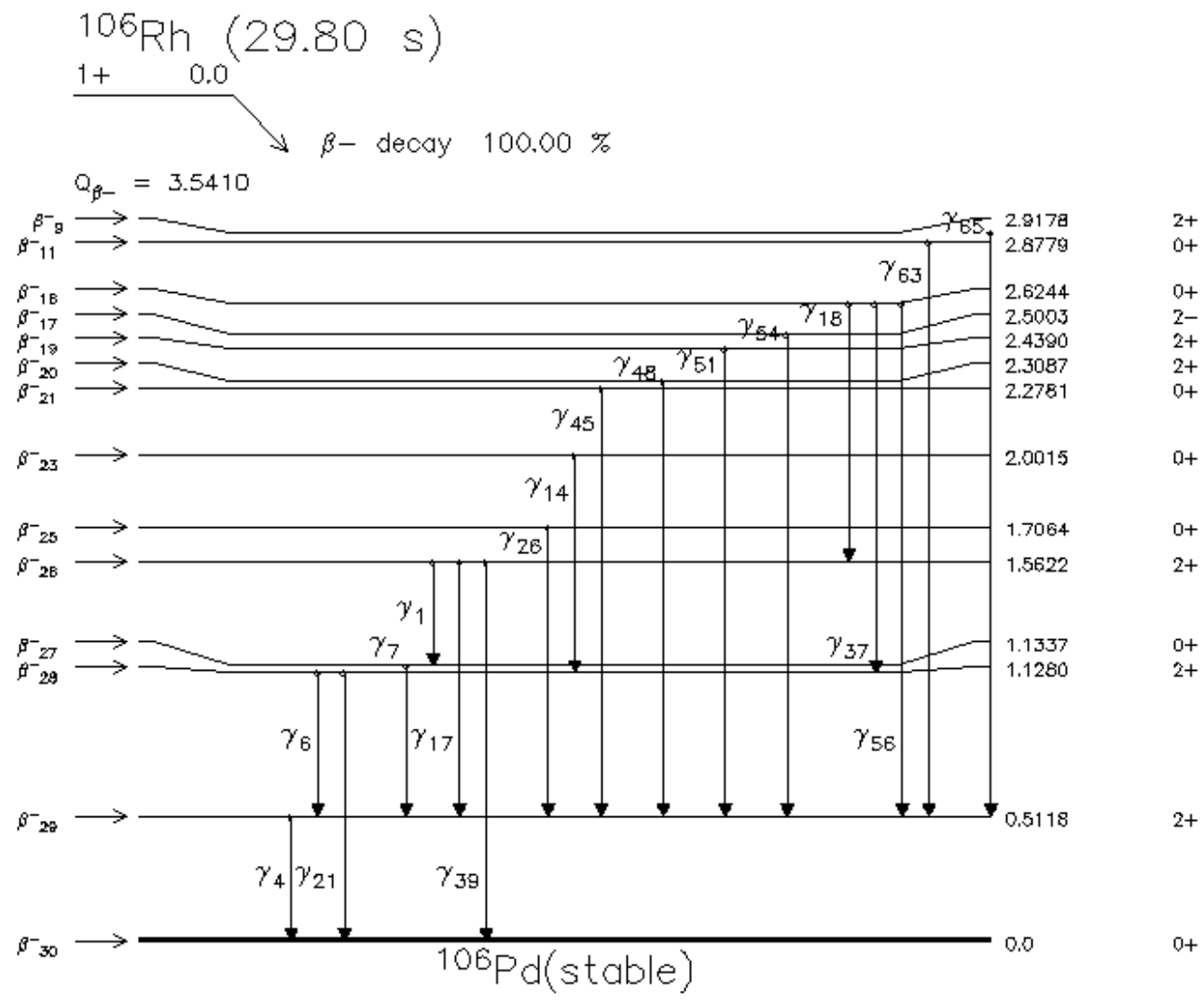

Figura 14: Esquema dos decaimentos radioativos do $R u$-106 até Pd-106 (https://www.orau.org/ptp/PTP\%20Library/library/DOE/bnl/nuclidedata/MIRRh106.htm)

\subsection{A escolha do radionuclídeo:}

O Rutênio-106 foi o Radioisótopo escolhido para aquisição. O Rutênio é mais utilizado na Europa e o I-125 nos EUA. Já foi mostrado as vantagens e desvantagens de ambos os isótopos, e o fator decisivo foi o financeiro, visto menor custo e maior duração da meia vida da placa de Rutênio. A maior vantagem do I125 é a possibilidade no tratamento de lesões um pouco maiores, $10 \mathrm{~mm}$ contra 7,0 mm do Rutênio, no entanto sua meia vida mais curta, 59,6 dias em relação aos 373,6 dias do Rutênio, necessitando de troca do radionuclídeo com maior frequência e toda a logística de transporte e armazenamento que isto implica. 
Foram adquiridas as placas $\mathrm{CCB}$ e $\mathrm{COB}$ (notch), pois com elas é possível cobrir a maioria dos casos devido ao seu diâmetro maior (de $20 \mathrm{~mm}$ ), e a abertura para o nervo óptico da placa COB permite tratar as lesões próximas.

As fontes de I-125 oftálmicas são vendidas pelo IPEN, cujo valor é de $R$ \$ 930,00 por semente e normalmente são solicitadas 24 sementes a cada 3 ou 4 meses, totalizando ao ano em torno de $\mathrm{R} \$ 70.000,00$. Soma-se a isso o valor de aquisição do software de planejamento, com valor médio de $R \$ 200.000,00$, e ainda maior investimento em proteção radiológica principalmente para manuseio e preparo de montagem das placas com as sementes de lodo. A placa de Rutênio tem um custo de $\mathrm{R} \$ 60.000,00$ e pode ser utilizada por até 2 anos, não necessitando de montagem nem de software de planejamento, diminuindo custos com equipamentos de proteção radiológica e conferindo menor exposição da equipe.

\section{PROTOCOLOS DE IMPLEMENTAÇÃO:}

\subsection{Descrição da área:}

A fonte ficará armazenada em área controlada, na sala quente do setor de radioterapia, dentro do seu próprio contêiner, com sinalização conforme a norma: Símbolo Internacional de presença de radiação e informação sobre a fonte.

A colocação das placas é realizada no centro cirúrgico e durante a cirurgia a placa fica armazenada em um container com blindagem suficiente para conter a radioatividade e reduzir a exposição da equipe.

Após a colocação da placa o paciente será alocado em um quarto especial, com identificação de área controlada, onde serão afixados em local visível os seguintes elementos gráficos:

I - Símbolo internacional de presença de radiação ionizante; 
II - Plano de ação para situação de emergência contendo a identificação dos responsáveis a serem acionados em situação de emergência e seus telefones para contato.

O número e características das fontes de radiação utilizadas no tratamento devem estar disponíveis no prontuário do paciente.

O quarto escolhido foi o maior disponível no setor, com apenas um quarto vizinho, e o mais próximo do corredor que dá acesso a uma área com menor circulação de pessoas. Recomenda-se ao paciente manter a proteção de $0,5 \mathrm{mmPb}$ no olho o maior tempo possível. São fornecidos colete e protetor de tireoide aos acompanhantes e são orientados a manter uma distância segura de 2,0 metros do paciente. Apesar da taxa de dose ser relativamente baixa já a uma distância de 1,0 metro, mantém-se os princípios de radioproteção, tempo, distância e blindagem, no intuito de reduzir a exposição a níveis mais baixos e seguros.

\subsection{Atribuições dos trabalhadores:}

\section{a) Oftalmologia}

A avaliação inicial é realizada pelo oftalmologista com experiência no diagnóstico e manejo do melanoma uveal.

Os seguintes exames devem ser realizados:

Exames clínicos: história do paciente de câncer, oftalmoscopia binocular indireta com foto-documentação (morfologia, topografia, tamanho do tumor) e desenho esquemático; exame de lâmpada de fenda, transiluminação.

Poderão ser solicitados angiografia pelafluoresceína e indocianina verde; ultrassonografia (padronizada A e B): dimensões tumorais (espessura, diâmetro) e topografia, diagnóstico diferencial (metástases uveais, hemangioma, melanocitoma 
e lesões hemorrágicas), fatores prognósticos (localização, morfologia, volume tumoral, vascularização).

As informações obtidas serão relatadas em prontuário e encaminhadas junto ao paciente para a consulta com o rádio-oncologista. Uma ficha de encaminhamento foi elaborada, vide anexo 2.

\section{b) Rádio-oncologista}

Após a avaliação e exames realizados pelo oftalmologista, o paciente deverá ser encaminhado com seus exames e o estadiamento clínico.

Exames de tomografia computadorizada (CT) e/ou ressonância magnética (RNM) não são obrigatórios. A doença metastática deve ser excluída, por exemplo, por imagem de ultrassonografia do fígado.

O estadiamento deverá ser realizado de acordo com TNM para melhor registro e comparação de dados (TNM 7º edição - American Joint Cancer Comitee - AJCC).

Após o estadiamento, o radio-oncologista avaliará se o paciente possui indicação de braquiterapia com a fonte de Ru-106.

As principais indicações para a braquiterapia são tumores de pequeno e médio porte.

Tumores muito pequenos (até 2 - $3 \mathrm{~mm}$ de espessura (T1) sem qualquer tendência de crescimento devem ser observados e tratados apenas em caso de crescimento. Estes tumores candidatos para a braquiterapia da placa ocular (Ru106 / I-125), que pode ser combinada com alguma forma de terapia a laser.

Tumores de tamanho médio com uma espessura de até $5 \mathrm{~mm}$ (T2) precisam de tratamento ativo e são candidatos à braquiterapia da placa ocular.

Determinados casos com uma espessura tumoral maior que $5 \mathrm{~mm}$ (T3) até um máximo de 8 (10) $\mathrm{mm}$ podem ser indicados, mas para estes grandes tumores 
maiores a braquiterapia é preferencialmente realizada com um emissor gama (I125).

Tumores grandes com uma espessura $>8$ - $10 \mathrm{~mm}$ não devem ser tratados com braquiterapia, pois os resultados são ruins em termos de controle local e morbidade relacionada à radiação.

Tumores perto do disco óptico e da mácula (dentro de 1-2 mm) não são candidatos ideais para braquiterapia, uma vez que uma subdosagem na margem tumoral dificilmente pode ser evitada. Por outro lado, é comum morbidade significativa relacionada com a braquiterapia no disco óptico e ou na mácula.

Exceções destes princípios podem ser consideradas em situações específicas, onde as questões devem ser levadas em conta refletindo principalmente aspectos de qualidade de vida do paciente. Por exemplo, no caso de apenas um olho funcional restante portador de um melanoma uveal, este olho deve ser conservado o maior tempo possível com tanta visão quanto possível. No caso de doentes com um estado de saúde geral deficiente com uma expectativa de vida limitada e em doentes idosos, o olho doente também deve ser conservado o maior tempo possível por razões óbvias. Em tais situações, a indicação para braquiterapia deve ser tomada de forma mais generosa, por exemplo tumores espessos (> $8 \mathrm{~mm}$ ) ou tumores justapapilares podem ser incluídos na lista de indicação para braquiterapia placa ocular.

Após a consulta e constatado a indicação do tratamento, o radio-oncologista deve preencher, na pasta do paciente, os seguintes itens:

a. Nome e registro do paciente;

b. Anamnese;

c. Classificação da patologia com estadiamento; 
d. Dose total no volume alvo e pontos de referência;

e. Observações concernentes ao tratamento.

- Instruir o paciente sobre possíveis efeitos colaterais.

- Avaliar o paciente após a cirurgia.

-Ficar atento e anotar no livro de ocorrências, qualquer alteração ou imprevisto ocorrido no tratamento.

\section{c). Físico médico e supervisor de radioproteção}

a. Verificar a integridade da fonte, certificado, e presença da tabela com os dados dosimétricos para o cálculo da dose.

b. Supervisionar, em conjunto com o médico, a inserção da placa de Rutênio no centro cirúrgico.

c. Realizar o planejamento após receber do radio-oncologista, por escrito através da pasta de tratamento, as doses requeridas em cada ponto de referência, juntamente com o tipo de placa utilizada;

d. Fazer o cálculo do tempo necessário de permanência da placa;

e. Monitorar no centro cirúrgico a dose recebida pela equipe;

f. Após o procedimento verificar se o nível de radiação dentro da sala está normal;

g. Monitorar a dose no quarto para garantir se o acompanhante e a equipe irá receber doses menores que os limites permitidos.

h. Efetuar o controle de entrada e saída das fontes;

i. Realizar o procedimento de reexportação das fontes de Ru-106 a cada aquisição; 
j. Afixar no quarto em que o paciente ficará o símbolo internacional de presença de radiação ionizante, plano de ação para situação de emergência, e característica da fonte.

k. Treinar os profissionais para situações de emergência.

I. Estar presente na retirada das placas de Rutênio, colocar nos contêineres e levar até a sala quente.

m. Esterilização das placas e dummies.

n. Seguir as normas de segurança de proteção radiológica implementadas no serviço de Radioterapia;

\section{d) Técnicos em radioterapia}

Não têm participação no procedimento.

\section{e) Equipe de enfermagem}

No ANEXO 1 temos os procedimentos específicos e orientações da enfermagem.

a. Receber o paciente, fazer uma análise preliminar de suas condições e dar as primeiras informações sobre o tratamento;

b. Encaminhar para consulta médica;

c. Encaminhar até a sala de cirurgia;

d. Preparar os equipamentos necessários para a cirurgia e realização da Braquiterapia;

e. $\quad$ Estar presente na sala de cirurgia, juntamente com o médico, o físico e, verificando o estado geral do paciente;

f. Auxiliar o médico no posicionamento e retirada das placas de Rutênio;

g. Ao término da cirurgia, levar o paciente para o quarto controlado e dar as orientações necessárias. 
h. Estar presente na retirada das placas e levar para esterilização dentro do contêiner.

i. Monitorar o paciente para que ele não fique transitando dentro do hospital.

j. Seguir os procedimentos de emergência e normas de segurança e proteção radiológica implementadas no serviço de radioterapia.

\subsection{Instruções para o procedimento de Braquiterapia Oftálmica de baixa taxa de dose com Rutênio-106}

Anteriormente ao início da aplicação, o paciente deve ser esclarecido sobre o tratamento e da necessidade de sua colaboração para o bom andamento dos procedimentos.

Antes do início da cirurgia deve-se verificar:

- A identidade do paciente;

- A prescrição na ficha de tratamento;

- O tempo de permanência da placa;

- Integridade da placa de Rutênio;

- Modelo da placa a ser utilizada;

- Placa no container blindado;

No decorrer da cirurgia:

- Após o paciente estar anestesiado, o cirurgião irá verificar se os músculos oculares precisarão ser realocados caso interfiram na inserção da placa. Após uma transiluminação ocular é possível ver as sombras da lesão na esclera subjacente, deve ser dado de 2 a $3 \mathrm{~mm}$ de margem e colocar a placa falsa (dummy) verificando se toda a lesão foi coberta, verificar se a inserção e a sutura estão adequadas. 
Retirada da dummy, e inserir a placa de Rutênio e fazer a fixação o mais rápido possível.

Monitorar os níveis de dose durante o procedimento.

Paciente ficará em quarto especial com medidas de radioproteção adotadas:

- Símbolo internacional de presença de radiação ionizante;

- Plano de ação para situação de emergência contendo a identificação dos responsáveis a serem acionados em situação de emergência e seus telefones para contato.

- O número e características das fontes de radiação utilizadas no tratamento devem estar disponíveis no prontuário do paciente.

$\mathrm{Na}$ retirada da fonte monitorar os níveis de dose no ambiente e nos IOE(s).

Esterilização das placas no contêiner e coloca-la na sala quente.

Registre os detalhes de tratamento na ficha do paciente (Anexo 3) não se esquecendo de incluir:
a. A data;
b. O tipo de placa utilizada;
c. O tempo total;
d. A dose total para cada área alvo ou ponto de interesse (Ápice, esclera).

\subsection{Procedimento cirúrgico:}

$\mathrm{Na}$ inserção, a cirurgia dura por volta de 40 minutos, o paciente é sedado com anestesia geral, depois os cirurgiões oftálmicos iniciam o procedimento, com as seguintes etapas: Peritomia conjuntival (Figura 15a), reparo dos músculos retos, desinserção do músculo reto do quadrante que está o tumor, localização e delimitação do tumor na esclera usando um transiluminador (Figura 15b). 
O tumor é localizado por iluminação transescleral e o GTV e ou o CTV são marcados com precisão na esclerótica sobreposta. Com base nessa marcação, que indica a borda externa da lesão, a placa adequada é escolhida, dando uma margem de 1 a $2 \mathrm{~mm}$ das bordas e levando em conta os resultados do ultrassom. É usada a placa falsa (dummy) para verificar o posicionamento, após bem delimitado e localizado, a fonte é substituída e a placa de Rutênio-106 é suturada sobre a lesão com Mersilene 5-0 (figura $15 \mathrm{c}$ ), a conjuntiva é suturada com Vicryl $6-0$, e feito curativo oclusivo com pomada de corticóide e antibiótico.

Ao encaminhar o aplicador para o oftalmologista que executa o procedimento cirúrgico, deve ter-se cuidado que a superfície de irradiação côncava do aplicador esteja sempre direcionada para material absorvente de radiação.

A retirada da fonte é mais rápida, por volta de 15 minutos, ao invés da anestesia geral, é realizado um bloqueio local, e os músculos são reinseridos.

O tempo de exposição da equipe com a fonte radioativa é no máximo 15 minutos por procedimento, entre inserção e retirada.
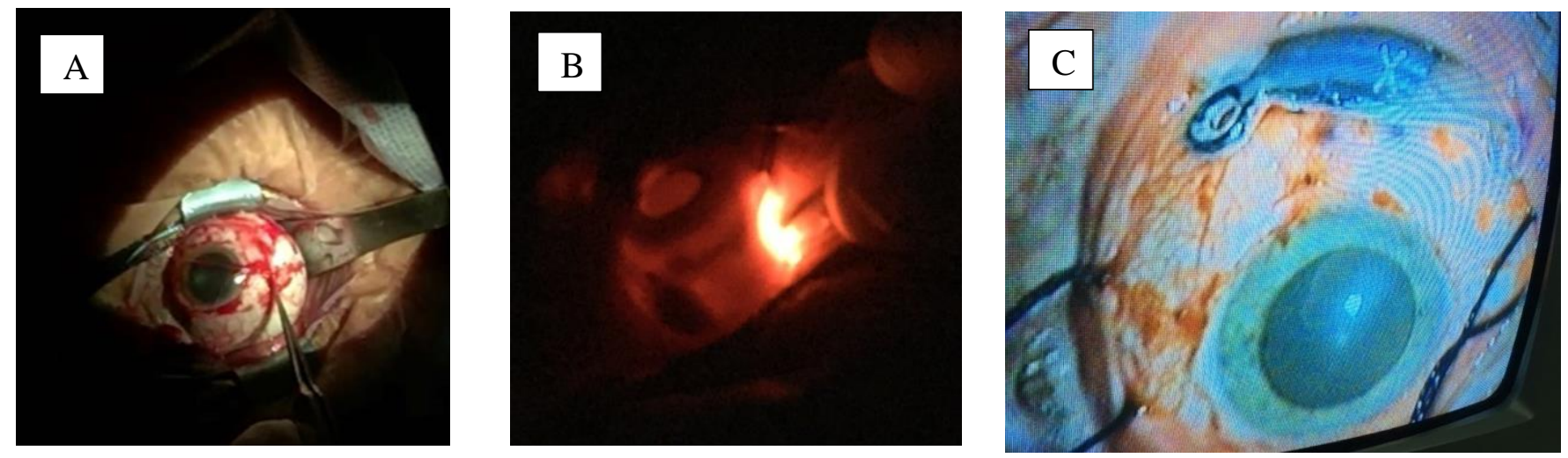

Figura 15: Etapas do procedimento cirúrgico, fotos do arquivo pessoal. 


\subsection{Esterilização da placa de Rutênio-106:}

Após cada uso, o usuário deve limpar imediatamente cada aplicador de Rutenio-106 com água, etanol ou um detergente neutro. Nunca utilize produtos ácidos ou corrosivos.

Banhos de ultrassom também podem ser usados para a limpeza das placas, mas não ultrapasse mais do que 5 min (100W no máximo) para evitar danos no aplicador.

Se a limpeza não for possível imediatamente após o uso, os aplicadores de Ru-106 podem ser armazenados em água ou etanol em algumas horas para prevenir que qualquer fluido se fixe na superfície.

O aplicador deve ser cuidadosamente limpo com detergentes à base de água destilada, em seguida, lavado em etanol, e deixar secar ao ar livre. Espere que o aplicador esteja completamente seco antes de ser colocar no recipiente de armazenamento.

Se for necessária uma limpeza mais mecânica, lave o aplicador apenas com um algodão úmido. Se a limpeza não tem sido bem-sucedida, por favor, entre em contato com o fabricante.

Dessa forma é recomendado apenas o etanol, Optal (n-propil-álcool) ou de ebulição e água destilada para a desinfecção desses aplicadores.

Pode ser que o aplicador escureça após algum tempo de uso, não é necessário que isso seja removido, é natural da placa. Isso não afetará a eficácia ou as condições de utilização do aplicador de forma nenhuma.

Quando a recomendação para a esterilização é: temperatura a $134^{\circ} \mathrm{C}$, pressão de 3 bar por aproximadamente 7 minutos. 
No serviço o Físico é o responsável pela esterilização da placa, que é feita com álcool $70 \%$ e detergente enzimático. A enfermagem faz apenas a esterilização do container em ácido peracético ou óxido de etileno.

\subsection{Procedimentos de Controle de Qualidade}

As placas de Rutênio-106 já virão com certificado de calibração em laboratório primário, atendendo aos requisitos de padronização estabelecidos por organismos nacionais e internacionais.

A fonte é produzida com atividade de 17 a $19 \mathrm{Mbq}$, a fabricante fornece também tabelas que leva em conta o decaimento e os parâmetros da distribuição de dose.

Todos os certificados bem como o número de série e modelo das placas serão checados. Caso seja constatada alguma irregularidade as placas serão devolvidas.

Verificação se a radiação de fuga quando a placa está no contêiner está dentro dos níveis permissíveis.

A placa tem vida útil de até 2 anos da data de fabricação ou 50 usos.

O manuseio e a preparação de aplicadores de fontes de radiação de Braquiterapia de baixa taxa de dose serão feitos com o uso de pinças de forma a proporcionar o afastamento mínimo de $15 \mathrm{~cm}$ entre o operador e as fontes de radiação.

Será expressamente proibido o manuseio de fontes seladas por profissionais sem treinamento específico e sem a utilização de equipamento de proteção individual.

Os recipientes utilizados no deslocamento de fontes seladas serão sinalizados com o símbolo de presença de radiação e ter a identificação da fonte de radiação. 
O inventário das fontes seladas em braquiterapia de baixa taxa de dose será feito antes e após os implantes temporários ou permanentes.

Assim, com todas essas medidas especiais de segurança, prevenirá a remoção acidental ou não autorizada das placas de Rutênio.

\subsection{Dosimetria:}

A dosimetria com fonte selada emissora de partículas beta apresenta diversas dificuldades, principalmente pelo curto alcance das partículas e o alto gradiente de dose à pequenas distâncias, que causa um impacto significante dosimetricamente. Aliado a isso temos o fato dos tamanhos dos detectores disponíveis para o uso bem como o formato curvo das placas causam ainda mais incertezas no processo.

De acordo com o descrito na literatura as incertezas estimadas variam de $8 \%$ a $14 \%{ }^{17-19}$ dependendo da profundidade analisada, do simulador escolhido e do dosímetro utilizado. Esse valor parece ser bem alto quando comparamos com dosimetria de fótons em teleterapia, em que as medidas estão de acordo com até 1 \% de variação. Entretanto as incertezas da dosimetria das partículas betas podem ser convertidas como incertezas espaciais, como menores de 0,5 mm, que estão de acordo com as incertezas associadas ao posicionamento. Por tanto é crucial conhecer as incertezas, problemas na geometria e as dependências do dosímetro escolhido.

Apesar de não ser necessária uma dosimetria das placas de Rutênio-106, por já virem certificadas do laboratório e também devido as incertezas associadas, é interessante ao menos simular uma situação para aferir a dose.

Foi irradiado um filme dosimétrico Gafchromic EBT3® da empresa Ashland(C separado por 5,0 mm de água da placa, simulando uma dose de 300 cGy, o 
resultado obtido pelo software OmniPro® da empresa IBA dosimetry (C) foi de 319,9 cGy. (Figura 16).

Apesar de todas as incertezas dosimétricas e de set-ups, a variação de 6,7\% da dose absoluta está bem condizente ao encontrado na literatura.

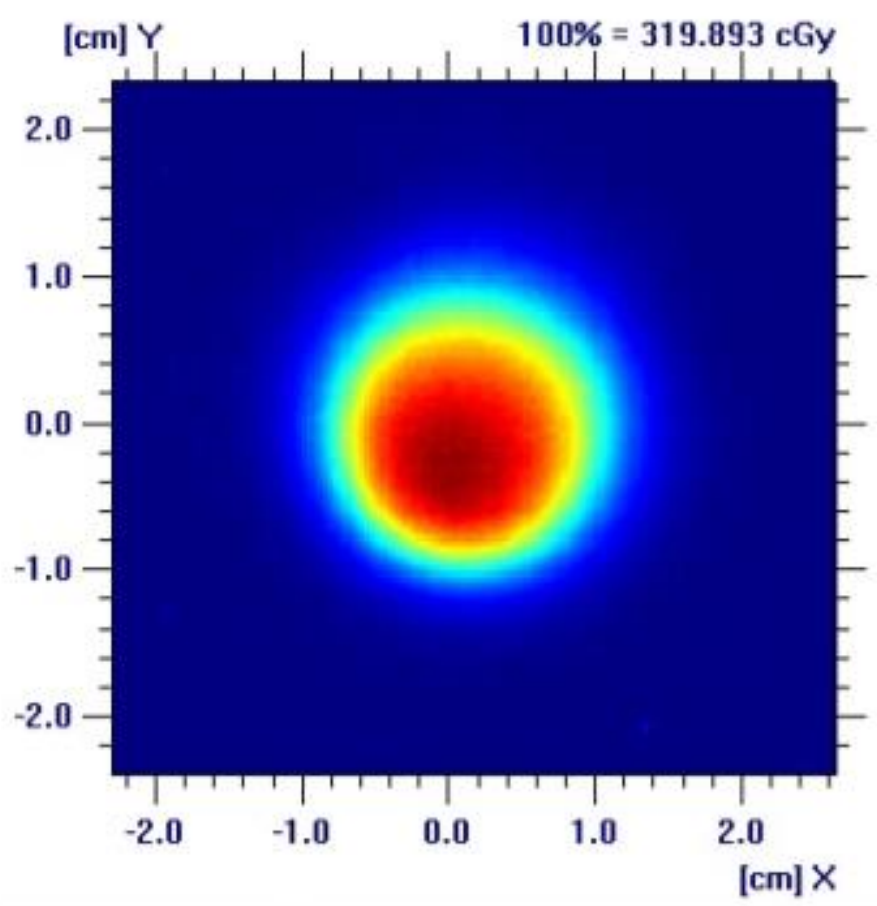

Figura 16: Distribuição de dose da placa de Ru-106.

\subsection{Monitoramento das Doses:}

Durante o procedimento de inserção e retirada, o cirurgião fica no máximo 15 minutos em contato com a fonte, exposto à uma taxa de dose média de 0.2 $\mathrm{mSv} /$ hora nas mãos e $0,03 \mathrm{mSv} / \mathrm{h}$ no tórax. Os limites de dose anuais aceitos para Indivíduos Ocupacionalmente Expostos pela norma da Comissão Nacional de Energia Nuclear (CNEN 3.01), é de 500 mSv e 20 mSv para extremidades e tórax respectivamente. Assim um cirurgião teria que realizar mais de mil procedimentos ao ano sem atingir o limite de dose. 
Já para os acompanhantes, a taxa de dose média à uma distância de 1,0 metro e 2,0 metros é de $6 \mu \mathrm{Sv} / \mathrm{h}$ e $3 \mu \mathrm{Sv} / \mathrm{h}$ respectivamente. As doses anuais para indivíduos do público é de $1000 \mu \mathrm{Sv}$, assim o acompanhante poderia ficar seguramente mais de 10 dias com o paciente sem atingir os limites de dose anual.

\subsection{Procedimentos de emergência:}

Por se tratar de radiação beta, e a característica da fonte ser de baixa taxa de dose, os níveis de radiação são bem baixos. Caso a fonte se solte do paciente, $O$ simples ato de pegar a fonte com uma pinça alongada e coloca-la no próprio contêiner já é suficiente para evitar níveis altos de exposição.

Os procedimentos de emergência devem ser adotados nas seguintes situações:

Desprendimento da placa durante a cirurgia;

Desprendimento da placa durante o tratamento;

a. Colocar a placa de Rutênio com o auxílio de uma pinça alongada dentro do container de emergência.

b. Informar ao supervisor de radioproteção o ocorrido;

c. Supervisor irá verificar se os níveis de dose estão seguros dentro do quarto.

d. Todos os registros de tratamento e ocorrências deverão ser impressos e recolhidos;

e. Informar aos médicos e físicos o horário do acontecimento para que se calcule a dose recebida pelo paciente, e a necessidade de um replanejamento.

f. Os dosímetros do pessoal envolvido durante este procedimento de emergência deverão ser lidos em caráter de urgência; 
g. Informar a CNEN sobre o fato, pessoal envolvida e medidas que foram tomadas.

No caso de incêndio das instalações:

a). Retire o paciente, comunique o corpo de bombeiros (se necessário), a segurança do hospital e o físico do Serviço;

b). Indique aos bombeiros o local de fontes radioativas e, após o acontecido, isole o local.

\subsection{Procedimentos da enfermagem para pacientes com fontes de Rutênio-}

\section{6 placas oftálmicas}

Instruções Gerais:

O paciente com a placa de Rutênio-106 pode irradiar externamente outras pessoas no quarto. Trata-se de uma fonte selada, rígida. A radiação beta emitida pelo $\mathrm{Ru}-106 / \mathrm{Rh}-106$ tem uma energia máxima de 3,54 MeV que deposita quase toda sua energia próxima a região a ser tratada, a maior parte da radiação é absorvida pelo próprio paciente, no entanto são necessárias medidas de Radioproteção para minimizar a exposição.

\subsection{Proteção radiológica:}

a) Transporte do paciente para o quarto

O transporte do paciente, da Radioterapia para o quarto, é realizado pelo atendente da Radioterapia com a orientação da equipe de física médica, de acordo com as normas de transporte interno de material radioativo. Se o elevador for utilizado, este deve ser o destinado a pacientes, e somente profissionais envolvidos no procedimento devem permanecer junto ao paciente durante o transporte. Utilizar 
protetor de chumbo sobre o olho implantado do paciente para reduzir o máximo possível o nível de exposição.

b) Visitas e acompanhantes

- Estão proibidas as visitas para menores de 18 anos e mulheres gestantes;

- As visitas permitidas deverão manter uma distância prudente do paciente de cerca 2 metros;

Cuidados com o Paciente

Os cuidados com o paciente devem ser efetuados observando-se os conceitos de proteção radiológica, ou seja, tempo, barreira e distância.

Como essas fontes são SELADAS e não são absorvidas pelo organismo do paciente, NENHUMA PRECAUÇÃO ESPECIAL É NECESSÁRIA quanto a dejetos como urina, vômitos, saliva, fezes, suor, ou objetos de uso pessoal.

Limitações

Embora o paciente esteja praticamente normal, deambulando e com seus afazeres normais, este paciente NÃO PODE, SOB NENHUM PRETEXTO, SAIR DO QUARTO.

Poderá, entretanto, circular com algumas restrições dentro do quarto e em casos especiais, com autorização do supervisor em proteção radiológica, receber visita. Caso o paciente seja criança ou necessite de acompanhante, este deverá ser informado sobre os cuidados de proteção radiológica. Caso algum acompanhante autorizado pernoite com o paciente, estes devem vestir coletes de chumbo e protetor de tireóide.

Higiene

Os procedimentos de limpeza do quarto devem ser efetuados apenas se forem necessários, diminuindo o tempo de permanência do pessoal no quarto. Desde que 
o paciente esteja em bom estado geral, ele poderá tomar banho ou fazer sua higiene íntima sozinho.

Visitas

Gestantes e pessoas menores de 18 anos não poderão visitar o paciente durante o período em que as fontes radioativas estiverem no paciente. Lembramos que as visitas estão limitadas a critério médico e radiológico. As visitas deverão ser aprovadas antecipadamente pela proteção radiológica. Somente em casos especiais será permitido acompanhante (veja o item Limitações). A ENFERMAGEM é responsável pelo seguimento das regras dos visitantes.

\section{Retirada das Fontes}

Como as fontes são inseridas e retiradas cirurgicamente, a enfermagem não tem responsabilidade sobre este procedimento. Os pacientes NÃO PODEM receber alta até que uma verificação final seja feita para verificar se todas as fontes foram removidas.

\subsection{Procedimentos de Emergência}

Por se tratar de radiação beta, e a característica da fonte ser de baixa taxa de dose, os níveis de radiação são bem baixos. Caso a fonte se solte do paciente, $\mathrm{O}$ simples ato de pegar a fonte com uma pinça alongada e coloca-la no próprio contêiner já é suficiente para evitar níveis altos de exposição.

1. Colocar a placa de Rutênio com o auxílio de uma pinça alongada dentro do container de emergência.

2. Informar ao supervisor de radioproteção o ocorrido;

3. Supervisor irá verificar se os níveis de dose estão seguros dentro do quarto.

4. Informar aos médicos e físicos o horário do acontecimento para que se calcule a dose recebida pelo paciente, e a necessidade de um replanejamento. 
Cuidados de emergência podem ser administrados com as fontes no paciente, tomando-se o cuidado de manter-se à maior distância possível e diminuir o tempo próximo ao paciente. Se o paciente for removido para qualquer outro setor (Imagens, UTI, etc), este deve ficar isolado de outros pacientes e o físico e o radioterapêuta devem ser chamados imediatamente pelos seguintes telefones: 
15 ANEXO 2 - FICHA DE ENCAMINHAMENTO DA OFTALMOLOGIA

\begin{tabular}{|l|l|l|}
\hline Paciente: & Idade: & \multicolumn{1}{|}{-1} \\
\hline Registro: & & ( )M ( $\mathrm{F}$ \\
\hline
\end{tabular}

\section{Oftalmologia - preencher todos os campos}

Médico Responsável:

CID / Diagnóstico:

Estadiamento AJCC:

Diametros da base:

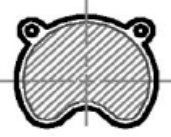

$C O B$

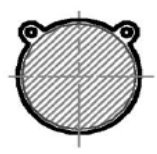

$C C B$

a.Radial: $\mathrm{mm}$

( ) notch

( ) sem notch

b.

Ápice + esclera: $+\ldots \mathrm{mm}$

Data da inserção:

Cor da Íris:

( ) OD

( ) OE

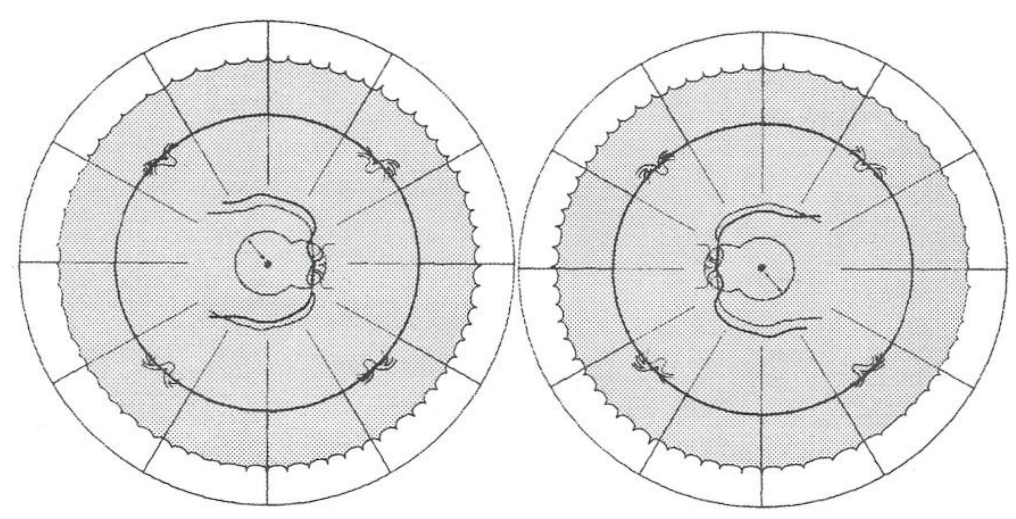


16 ANEXO 3: FICHA DE TRATAMENTO DESENVOLVIDA DO HOSPITAL REGIONAL DO CÂNCER DE PASSOS - MG

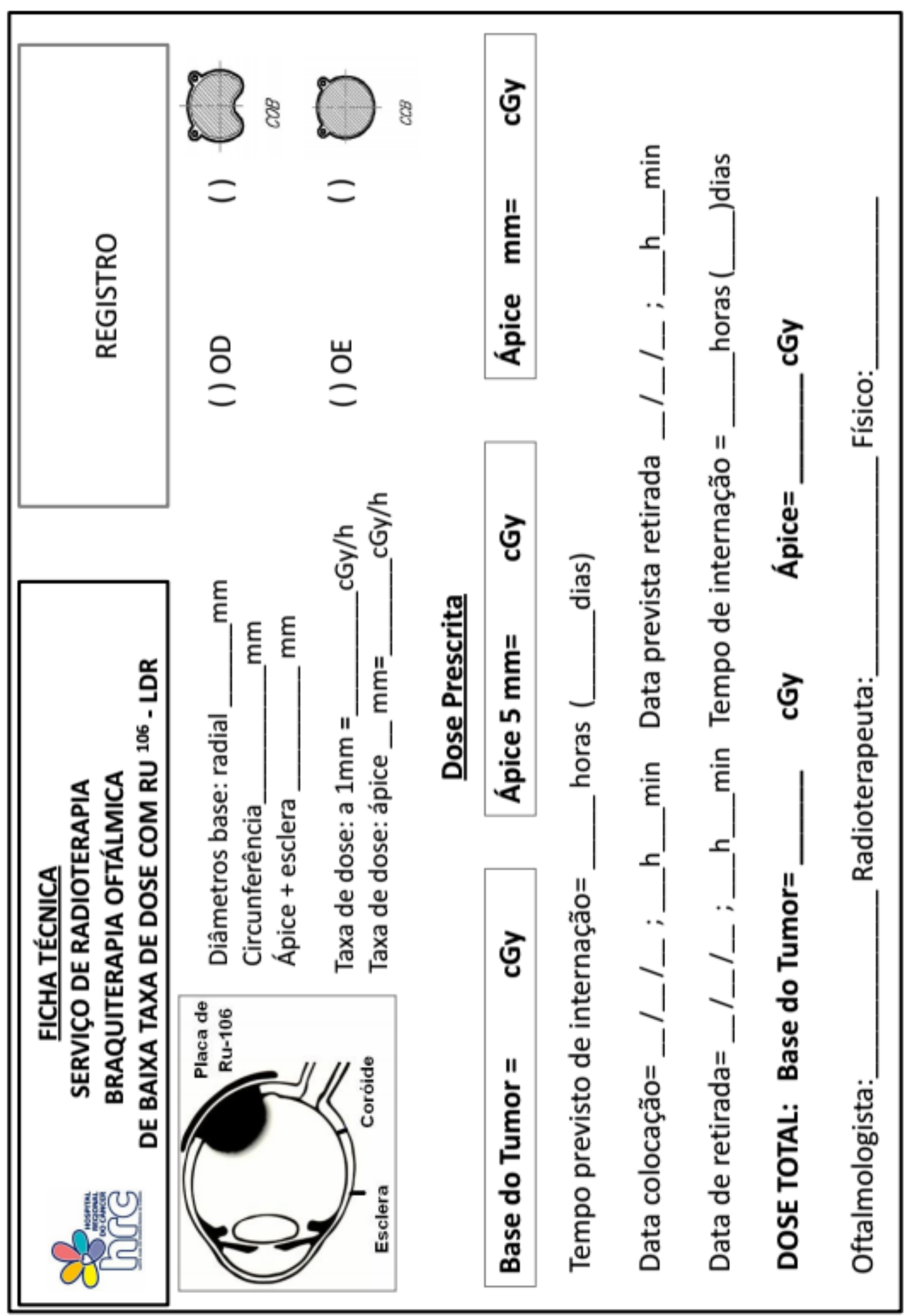

